\title{
ORIGINAL PAPER \\ Occupational Stress and Catholic Priests: A Scoping Review of the Literature
}

\author{
Miguel Ruiz-Prada ${ }^{1}$ - Samuel Fernández-Salinero ${ }^{2}$ - Cristina García-Ael ${ }^{1}$. \\ Gabriela Topa ${ }^{1}$ (D)
}

Accepted: 15 July 2021 / Published online: 15 August 2021

(c) The Author(s) 2021, corrected publication 2021

\begin{abstract}
This study offers an exploratory review of the experience of stress and burnout syndrome among Catholic priests. Following Arksey and O'Malley's (Int J Soc Res Methodol 8(1):19-32, 2005, https://doi.org/10.1080/1364557032000119616) protocol, a scoping study was conducted. Given the scarcity of studies found on the subject, a broad selection criterion was used, which included quantitative, qualitative and mixed studies, literature reviews and comparative studies with other professions. The results reveal various risk factors: work overload among younger generations of priests, a sociocultural context that distrusts the clergy, neurotic, introverted, perfectionist and narcissistic personality styles, avoidant and complacent coping styles, living alone, not having sufficient support (especially from the Church authorities), excessive demands and lack of boundaries related to the priestly role and submissive obedience styles, among others. However, the studies reviewed also identified important protection factors: promoting optimism, an approach-based coping style and a collaborative way of resolving conflicts, frequent physical exercise, eating a balanced diet, finding time to rest, strengthening personal identity, social support (from parishioners, collaborators, colleagues, superiors) and leading an active spiritual life. Stress and burnout are associated with certain pathologies linked to smoking, alcoholism, obesity, diabetes, cardiovascular disease, anxiety and depression. Strengthening protective factors and minimizing the impact of risk factors would do much to improve the clergy's occupational health.
\end{abstract}

Keywords Priests $\cdot$ Clergy $\cdot$ Occupational stress $\cdot$ Burnout

Gabriela Topa

gtopa@psi.uned.es

Extended author information available on the last page of the article 


\section{Introduction}

Down the centuries, no era in humanity's history has been free from stress, since each generation has had the challenge of facing a complex environment (wars, natural disasters, conflict, etc.). Stress has a positive dimension in that it has, throughout history, helped both individuals and societies to survive and make the most of their capacities. As such, stress helps increase resources and optimize productivity. Problems occur when this process of physical and psychological activation is sustained over long periods of time, since when this happens, resources are depleted, and performance suffers. It is therefore important to distinguish between "positive" stress or "eustress" and "negative" stress or "distress" (de Miguel et al., 2009; López, 2012).

One very common form of sustained stress or distress is occupational stress. According to person-environment fit theory, occupational stress occurs as a result of a misfit between the employee's capacities and the demands of the environment in which they perform their job. This misfit may in turn be due to the fact that either the person's aptitudes and capabilities do not correspond with those required by their job, or their job fails to satisfy their individual needs or expectations (López, 2012; Luceño et al., 2004).

Besides, recent research has demonstrated that clerical profession is related to complex work-related stress processes (Wells et al., 2012). When evaluating stress in clergy, it has been found that they experience stressors not only related to their careers, like counseling, teaching or guiding, but also effects of work stress expand to their personal lives. Even though recent research show that religious resources and emotional and spiritual well-being are related to positive coping strategies (Gall, 2000), there are scarce studies that evaluate stress processes among clergy.

Moreover, it should not be forgotten that the current labor market, which is increasingly complex and ever-changing, demands competitiveness, productivity and flexibility, which are experienced subjectively by employees as overload and pressure, giving rise to a wide range of occupational health-related pathologies, including absenteeism, burnout, occupational accidents and cardiovascular disease, among others (Gil-Lacruz \& Izquierdo, 2004; Luceño et al., 2004; Serrano-Orellana \& Portalanza, 2015). It has been demonstrated that clergy mental health may be improved via enhancing work resources. These measures have been related to positive outcomes such an improvement of spiritual well-being (Terry \& Cunningham, 2020). One of the main reasons underlying current research is the fact that in many ways, clergy have been usually ignored notwithstanding they constitute a high-risk population (Terry \& Cunningham, 2020). We believe that our research will help to identify the more common variables that impact in clergy occupational stress.

\section{Psychosocial Factors of Occupational Stress}

With its demands for competitiveness, the labor market often causes individuals with a "type A" behavioral pattern to fall victim to distress. These individuals are characterized by excessive ambition, a strong need for achievement, being perfectionists, being impatient and competitive, feeling a sense of urgency, being too hard 
on themselves and on others, and experiencing a constant feeling of dissatisfaction. They also tend to overreact to stressful situations (García et al., 2015; Gil-Lacruz \& Izquierdo, 2004).

Another internal aspect of the individual that has an impact on stress is the "locus of control"; in other words, the person's belief regarding whether the situations in their life can be controlled by their own decisions (internal locus) or are controlled by external forces (external locus). Individuals who have (mainly) an external locus of control are more vulnerable to stress because they believe that their success and good performance depend on other people or situations (Asante \& Affum-Osei, 2019).

In addition to these internal personality factors, there are also a number of other external stressors, which can be environmental, occupational and/or organizational in nature. These include: difficulties establishing a work-life balance, inflexible working hours, excessive tasks, repetitive tasks, difficulties linked to service beneficiaries, a feeling of having to be available round the clock, every day of the week, lack of limits in the performance of functions, excessive bureaucracy, structures which generate distrust, conflict with work colleagues, task ambiguity (unclear definitions), lack of positive challenging experiences, lack of recognition and supervision, poor occupational support and little participation in decision making (Durán, 2010; López, 2012).

One moderator variable of occupational stress is the attainment of rewards in the form of a good salary, social support, recognition and personal accomplishment, etc. Good rewards foster motivation, engagement (involvement in one's work) and job satisfaction, minimizing the impact of work-related demands, whereas intense physical and/or psychological effort accompanied by few/poor rewards gives rise to occupational stress (Bakker \& Demerouti, 2013).

\section{Burnout Syndrome and Boreout Syndrome}

When stress is sustained over long periods of time, it may result in what is known as burnout syndrome. This syndrome manifests as intense physical and emotional tiredness, depersonalization, cynicism (distant and insensitive attitude toward service beneficiaries; the subject isolates themselves in order to protect themselves) and low self-esteem (the individual feels unable to do their job, has no sense of personal achievement and feels overwhelmed by having to deal with others). This syndrome is common among those who work with people and who feel that those to whom they provide a service are very demanding; these individuals often feel a vocation, have strong ethical convictions and work in a context with scarce financial and organizational resources (Maslach, 2017).

This syndrome was first described by Herbert Freudenberger in 1974. Since then, it has been thoroughly studied and specified. However, neither the ICD-10 nor the more recent DSM-5 consider it a specific disorder. Although it is a syndrome that affects many helping professions, including priests, from a medical-legal point of view, it still cannot be diagnosed as an occupational disease (Chirico, 2017b). However, the ICD-11, which will enter into force in January 2022, describes burnout 
as a syndrome related to chronic work stress, thereby providing legal coverage for the decisions made by occupational physicians (prescribing sick leave, for example) (WHO, 2018).

Health professionals must also distinguish between depression and burnout, two disorders which share certain symptoms. However, whereas burnout refers specifically to the work context, depression is a more general, context-independent disease. Moreover, cynicism toward aid recipients (patients, users, clients, etc.) is fundamental in burnout syndrome and is not present in depression (Chirico, 2017a).

Burnout syndrome correlates negatively with both engagement and employees' perception of self-efficacy (Leiter \& Maslach, 2017). Salanova et al. (2005) carried out a study in which they discovered two dynamics which, in a spiral form, hampered or fostered confidence in personal self-efficacy when attaining personal success: burnout (downward spiral model) and engagement (upward spiral model). University students who, in the past, had obtained good academic results positively assessed their capacities and were confident of future success. In other words, the greater the individual's past academic success, the greater their perceived academic efficacy and the higher their levels of engagement. Burnout, on the other hand, was associated with a crisis of efficacy, further intensified by previous failures which anticipated future ones.

Some authors have recently started to talk also about boreout syndrome (Cabrera, 2014). This syndrome is characterized by three elements: the employee becomes bored because "they don't know what to do" during a large part of their working day or because the tasks they do are monotonous and tedious. The employee is disengaged: they do not identify with the company values and are not motivated, since they see no opportunity for advancement with the corresponding increase in responsibility, recognition and salary. Finally, the employee feels that not enough is demanded of them, since the organization assigns them few or irrelevant tasks, or those which do not challenge their personal skills and abilities. Employees themselves often perpetuate boreout syndrome by pretending to be overwhelmed by the amount of work assigned to them ("pseudo-burnout"), thereby avoiding any increase in workload: they fill their desk with documents, delay the completion of tasks and spend more time at work than their colleagues, etc. (Cabrera, 2014).

\section{Leadership Styles and Occupational Stress}

The type of leadership exercised by management in an organization or institution is another key variable to be taken into consideration. Traditional approaches to leadership support an "individualistic" understanding of this concept. Nevertheless, Social Identity Theory (Tajfel \& Turner, 1979) posits that leadership can be better understood as "something to do with the us" than as "something to do with the self." From this perspective, Haslam et al. (2011) argue that good leadership is that which is able to build an identity shared by both leader and followers. Leadership could therefore be defined as the "process of influencing other people in ways that motivate them to contribute to the achievement of collective goals" (p. 79). One key term 
in this approach is "influence," since what leaders seek is to make followers "want to do" what is asked of them.

Thus, organizations which engage in a traditional, pyramid-type leadership, in which management rigidly dictates how things should be done and employees follow instructions with no channel for making suggestions, do not seem the best positioned to foster engagement and job satisfaction. More inclusive models of leadership, however, based on the leader's ability to influence and include, and which seek to promote a flatter organizational structure, facilitating teamwork and networking, seem more conducive to proactive intrapreneurial behavior, which generates satisfaction and well-being among those who engage in it (Moriano et al., 2014). Let us remember that occupational stress occurs when the job fails to satisfy the employee's needs or expectations, and when the employee does not feel supported by their leader (Serrano-Orellana \& Portalanza, 2015).

In this sense, analyzed the modulating role of job engagement in the relationship between stress and job satisfaction. The sample comprised 779 professional soldiers from the Spanish Army. In general, the results indicated that, when levels of the two dimensions of job engagement analyzed (psychological identification and feelings of duty-obligation toward the job) were high, stress did not appear to affect job satisfaction. However, occupational stress did have an impact when job engagement was low.

\section{Occupational Stress and Burnout Among Priests}

Being a priest in today's world involves new challenges which can be highly stressful: globalization (fast-paced social, economic and cultural changes); secularization (loss of influence by religion and its institutions); large-scale decrease in religious practice; the importance of personal fulfillment (freer and more individualistic spiritual searches); priests' loss of status and standing (contradiction between the theological and sociological images of the clergy: whereas before they were powerful and respected, they are now considered marginalized, out-of-date and obsolete); drop in the number of priests and the general aging of the clergy; the promotion of women; and increasingly urban, technological and democratic societies, etc. (Cozzens, 2003; López, 2012; Lowney, 2018).

Burnout is a concern among the clergy. This was the conclusion drawn by López (2009) in her doctoral thesis. In a sample of 881 Catholic priests in Latin America, this author found that three out of every five suffered from this syndrome, in either its intermediate or advanced phase. Moreover, one out of every four suffered from severe burnout. A priest suffering from this disorder was found to be seriously damaged or simply unable to help others adequately.

Consistently with the approaches described above, and under the title "Los curas están estresados" (Priests are stressed), Vidal (2012) wrote an article in the newspaper "El Mundo" outlining the conclusions reached by participants at a conference held at the Salesian Pontifical University in Rome in March 2012 ("Preti sul lettino. Agio e disagio del servizio pastorale del clero"; "Priests on the Couch. Wellbeing and distress in pastoral work"). Some causes of stress experienced by priests 
(which on occasions becomes chronic and turns into burnout syndrome) include: their enormous workload (which increases as the number of clergy diminishes and they all grow older); being at their congregation's disposal at any time of the day or night; feeling like mere "dispensers of sacraments"; conflicts with fellow clergy (young-old; progressive-conservative); the excessive demands of some parishioners; increases in the number of those who are indifferent to priests, distant from them and even overly critical toward them; and living alone (not receiving enough affection) and working alone. The experts who met at the aforementioned conference identified three elements for coping with stress: prayer, priestly brotherhood (as a source of aid, refuge and consolation) and, when necessary, asking for help from a mental health specialist.

Two speakers at the conference held in Rome, Crea and Mastrofini, had previously (2010) published the work "Preti sul lettino" ("Priests on the Couch"). This book presented the results of recent research into the Italian clergy, which coincide with those presented so far in this paper: the clergy as a group is aging, priests live and work alone, the workload is increasing, and they feel dissatisfied and tired. Alongside these statistical data, the book also presented qualitative information provided by psychotherapists working with priests, who identified a wide variety of different problems: they feel indispensable, they do not feel understood, they cannot stand their collaborators, and they feel that, while their job is to provide aid, they have little training in emotional intelligence and social skills, etc.

In relation to burnout and boreout syndromes, seen as two opposing manifestations of occupational stress, López (2012) proposes distinguishing between three different types of priest when dealing with the challenges posed: those who are always exhausted, which results in a chaotic lifestyle (in terms of rest, diet, exercise, prayer and study, etc.) and a feeling of failure in their lives (burnout syndrome); those who minister to their flock without much enthusiasm, never fully developing as priests and denying their congregation the benefit of their talents and energy (boreout syndrome); and those who are able to do their job fully without detriment to their health, honoring their commitment faithfully with complete serenity.

One variable which has a notable influence on stress among priests is their experience of the "priestly role." Gnani (2013) claims that role conflicts are very common in priestly life and can cause high stress levels. A role conflict implies (at least) the presence of three elements: the individual (the priest himself), the group (the congregation to which he is assigned) and the organization (the diocese). To assume that role-related problems can be attributed solely to dynamics occurring within the individual ("Father $\mathrm{X}$ has a nervous temperament and finds it hard to accept change"), the limits of the institution ("the bishop is far away and doesn't understand what he is asking") or the characteristics of the group ("it's a difficult parish; it's a very cold congregation") is to see only part of the picture.

\section{Study Aims}

According to data published by the Spanish Episcopal Conference (2017), the Catholic Church in Spain currently has 16.334 diocesan priests and 6.745 priests 
belonging to religious orders who engage in pastoral work (23.079 priests in total). For its part, the Press Office of the Holy See (2019) set the number of Catholic priests in the world today at 414.582 (data from 2017). However, despite the large number of clergymen within the Catholic Church, hardly any studies have sought to explore how this group functions in terms of Social Psychology and Organizations, particularly in relation to experiences of stress.

It is true that, over recent years, the ecclesiastical authorities have expressed a growing interest in the contributions made by psychology to our understanding of human maturity and have begun to use this knowledge in both the initial training provided to seminarians (Congregation for the Clergy, 2016) and the ongoing training provided to priests (John Paul II, 1992). Nevertheless, a detailed search of the literature revealed only one rigorous study focusing on a sample of Spanish priests. This study was published by Gómez (2009) 10 years ago and emerged from the doctoral thesis carried out by the author, which explored psychological health and human fulfillment in a group of 770 priests and 753 lay people (comparison group) from all the autonomous communities in Spain.

The present study, therefore, aims to make a modest contribution to this neglected field of study, namely that of Catholic priests, from the perspective of Psychology. Due to the novelty and the lack of research in this field, following Arksey and O'Malley's (2005) suggestions, we conducted a scoping review. Scoping study tries to address topics and review literature but not to assess the quality of included studied (Arksey \& O'Malley, 2005). Besides, it has been stated that scoping studies are a rigorous and transparent method for mapping areas of research. Moreover, scoping review may be used for illustrating the volume, nature and other circumstances around the field of research. Last, this method may be seen as a method in its own right for contributing to the publication and dissemination of research findings. Having said this, the following aims are proposed:

1. To conduct an exploratory review of papers published in scientific journals which include any of the variables which influence the experience of work-related stress among Catholic priests.

2. To systematize and categorize the main results of the variables over work-related stress among Catholic priests.

3. To construct a basic theoretical framework for future research in this field in Spain.

\section{Method}

As mentioned above, scoping review method purposes a process which is documented in detail to enable the study to be replicated (Arksey \& O'Malley, 2005). For this purpose, we followed the steps of (Arksey \& O'Malley, 2005). The first stage of the process is to identity the research question. In our case, the research question was which are the factors related to stress among clergy? Scoping review literature suggests that researchers may not place strict limitations on search terms or relevant studies. In Table 1, steps of scoping review process may be seen. 
Table 1 Stages of the scoping review process

\begin{tabular}{ll}
\hline Stage & Important issues \\
\hline $\begin{array}{l}\text { 1. Identifying the research question } \\
\text { 2. Identifying relevant studies }\end{array}$ & $\begin{array}{r}\text { Define parameters and considering the implications } \\
\text { First aspect is to be as comprehensive and wide as possible. Define } \\
\text { appropriate terms, key concepts and define the search strategy } \\
\text { It is recommended to pick a large number of studies for, subse- } \\
\text { quently, eliminate those that don't address the central issue of our } \\
\text { research }\end{array}$ \\
$\begin{array}{l}\text { 3. Study selection } \\
\text { Perform a narrative review. Decide which information and variables } \\
\text { are important to be considered from the primary studies }\end{array}$ \\
$\begin{array}{l}\text { Include only a small percentage of the results reviewed. Scopus } \\
\text { review aims to present an overview of all the material. Scoping } \\
\text { reporting the results }\end{array}$ \\
\begin{tabular}{l} 
review does not seek to assess quality or evidence of the material \\
\hline
\end{tabular}
\end{tabular}

Extracted from Arksey and O’Malley (2005)

After defining the research question, we moved into the second stage of scoping review proposal, which is to identify relevant studies. This stage comprises the selection of databases, the selection of right terms and to pilot the search strategy. Besides, it comprises the strategy for limiting the abundance of results. When introducing the concept of "burnout," the PyscInfo Thesaurus (American Psychiatric Association-APA) requests that the term "Occupational Stress" be used more precisely. After several "trials" carried out in that same database, the following terms were chosen for use in all databases: ("Occupational Stress" OR "Stress") AND ("Clergy" OR "Priests"). In each database, a sufficiently "broad question" was posed in order to ensure a significant number of records were identified. In other fields in which there is an abundance of empirical evidence, it would have been possible to have been more "restrictive," limiting the target variables to a much greater extent (Urrútia, 2006), besides this is coherent with scoping review method.

Indeed, the ambiguity of the concepts "Clergy" and "Priests" (which include ministers from both other Christian denominations and other religions) was deliberate, since preceding them with the term "Catholic" resulted in almost no records being identified.

The search identified the following records: 181 studies in PsycInfo, 477 in Scopus, 258 in Web of Science, 116 in PubPsych and 173 in PubMed, making a total of 1,205 references.

Due to the abundance of literature on this topic, we decided to enter the following "limiters" into the aforementioned databases: only papers published in scientific journals, only papers published from the year 2000 onwards, and only papers written in English or Spanish. The year 2000 was established as a cutoff date because it was from that time onwards that the majority of research was conducted, and because all studies from that time onwards shared the same sociocultural context (i.e., the same environmental stressors). This is the third stage of Arksey and Malley's (2005) suggestions for scoping review method.

Again, a "broad" criterion was used here in order to ensure a sufficient number of records were identified. The results were as follows: 80 studies in PsycInfo, 83 in 
Scopus, 48 in Web of Science, 85 in PubPsych and 99 in PubMed, reducing the total number of records to 395 .

After reading the "Title" and the "Abstract" (and in some cases the "Method" section, particularly as regards the information given about participants), we selected those scientific papers which focused mainly on stress and referred to Catholic priests, either specifically, as part of a study on ministers from other faiths or in comparison with other professions.

Although the search was laborious, it was considered the best way of "recovering" all studies exploring stress among Catholic clergy. The final sample of studies comprised 14 scientific journal papers in PsycInfo, 10 in Scopus, 8 in Web of Science, 3 in PubPsych and 7 in PubMed, giving a total of 42. Once all duplicates had been removed, the final list comprised 26 scientific papers. The article selection criteria may be seen in Fig. 1.

Moreover, the papers selected referred to both priests belonging to religious orders and diocesan priests. In some cases, comparisons were made between the two

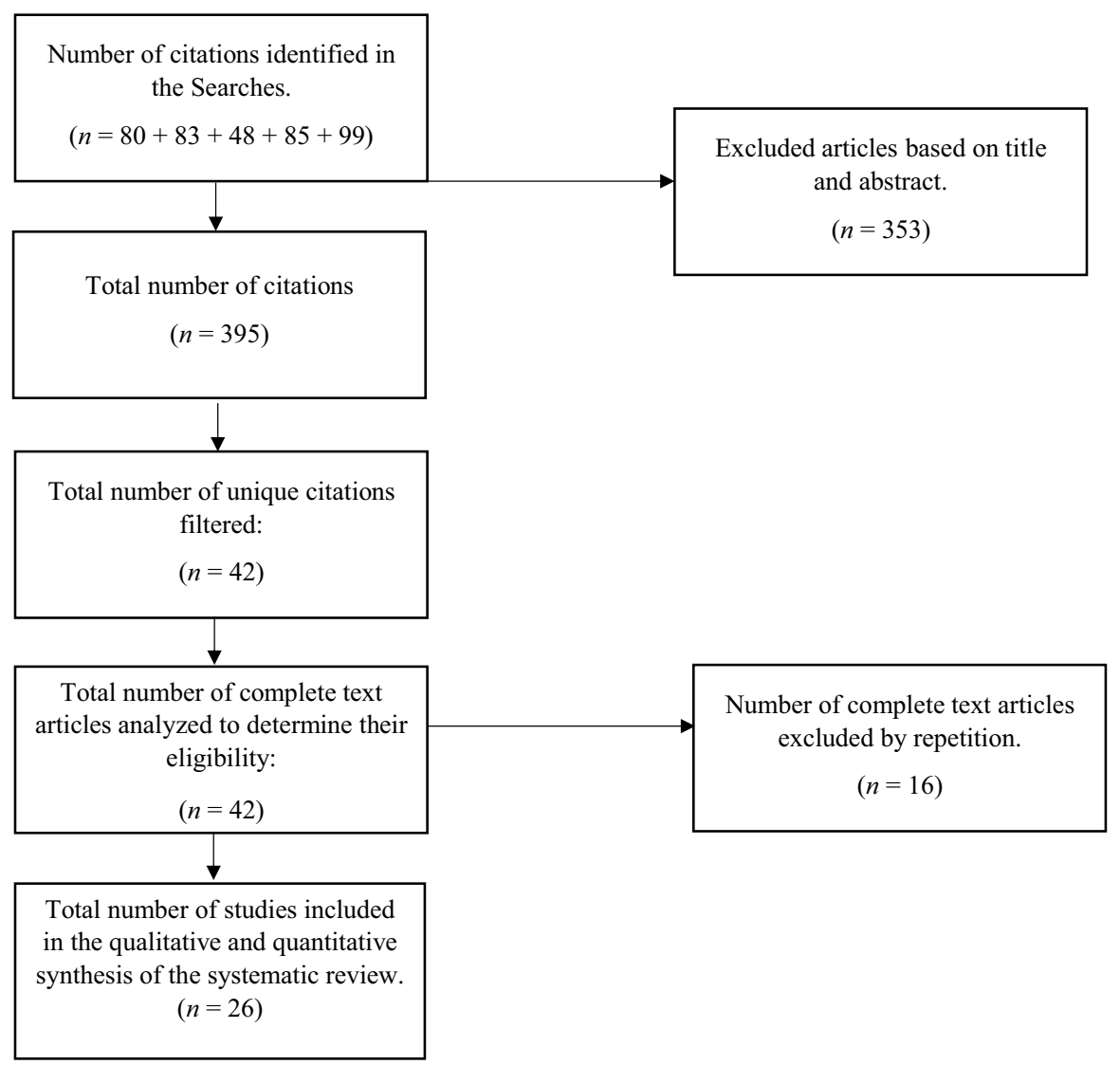

Fig. 1 Flow diagram of the information through the different phases. Adapted from Urrutia and Bonfill (2010) 
situations, while in others no distinction was made at all, even though the variables "loneliness" and "relationship with authorities" are experienced very differently by the two types of clergies.

\section{Results}

Following (Arksey \& O’Malley, 2005) scoping review steps, we moved into step four. This step is related to charting data. Authors propose an approach akin to a narrative review (Pawson, 2002). This is a very important step of our revision because it comprises the decision of selecting the important information that should be recorded for the selected studies. To this end, and following a narrative approach, there are six fields that should be addressed: (a) author(s) and year of publication, (b) study populations, (c) aims of the study, (d) methodological aspects, (e) outcomes measures and (f) important results (which may be seen as step five).

Conducting our review, the first difficulty identified in the selected studies was the need to adapt the measurement instruments to the language and vocational profile of Catholic priests. For example, the Maslach Burnout Inventory (Maslach et al., 1996) was reformulated in different studies, with the language being modified and items added to better reflect priests' experiences (e.g., the word "client" was removed from the questionnaires when referring to parishioners).

Some studies went even further and substituted the three components of burnout syndrome proposed by Maslach (emotional exhaustion, depersonalization and loss of personal accomplishment) for a two-component model measuring the balance between negative and positive affect. This is the proposal made by the Francis Burnout Inventory. Thus, when priests have high levels of negative affect and low levels of positive affect, this is linked to emotional exhaustion and poor work-related psychological health. On the other hand, if they have high levels of positive affect and low levels of negative affect, the results are associated with feelings linked to satisfaction with their ministry (Francis et al., 2017).

After reading the selected texts, and aiming to systematize our findings, the results obtained were grouped into the following variables, all of which affect occupational stress and burnout among Catholic priests. For systematizing the exposition, we have organized the results in the following categories: (a) sociodemographic variables, (b) psychological factors and coping styles, (c) living conditions, (d) sociocultural context, (e) demands of the job, (f) organizational variables, (g) comparative studies and (h) stress, burnout and health. For a complete revision of the results, Table 2 may be seen.

\section{Sociodemographic Variables}

Following to Arksey and O'Malley (2005) suggestions. We are analyzing factors related to study populations and its relationships with some important results. The first variable to bear in mind is priests' age. Some studies found that young priests perceive more pressure than older ones. One possible explanation for this is that age 


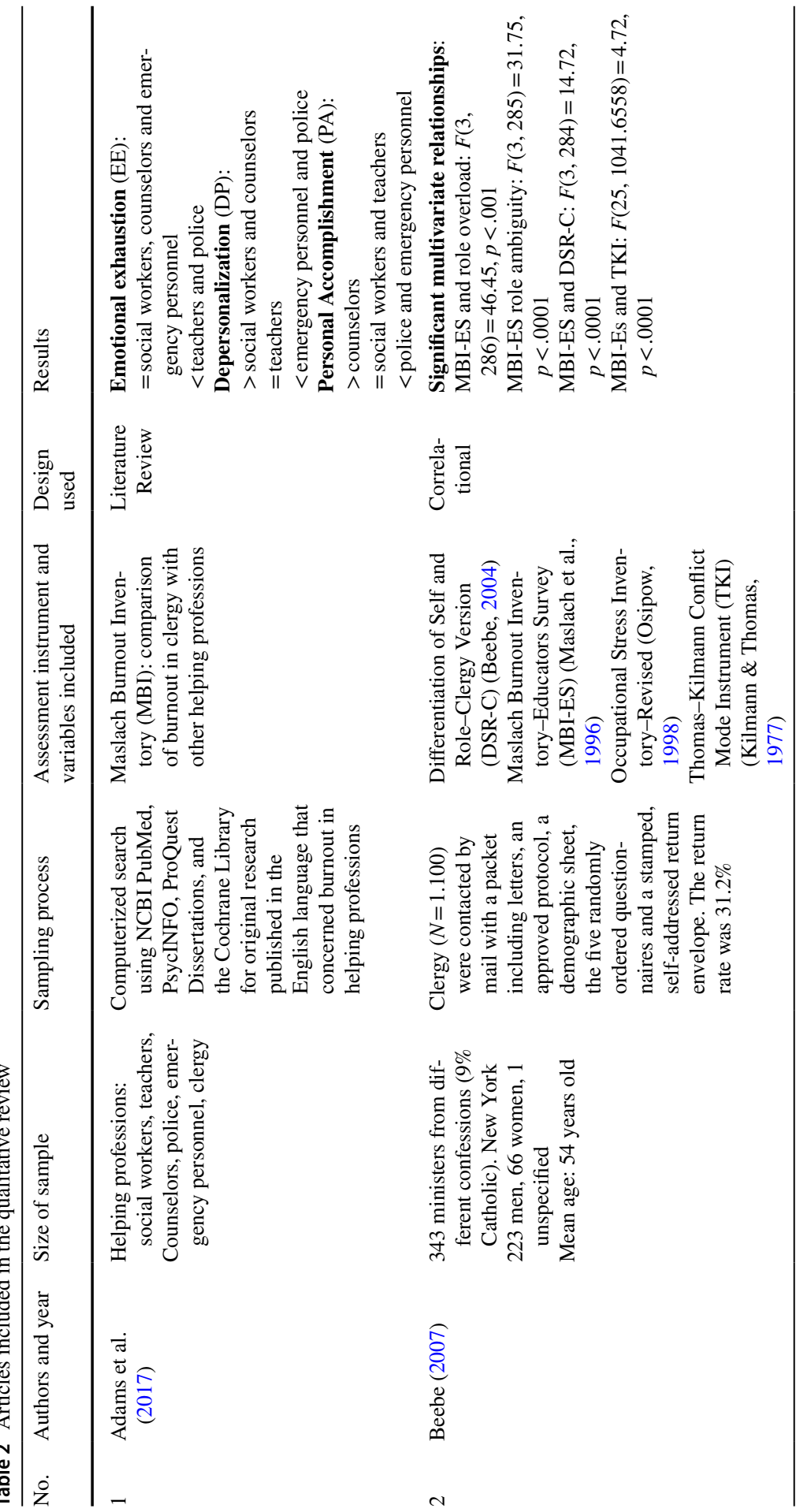




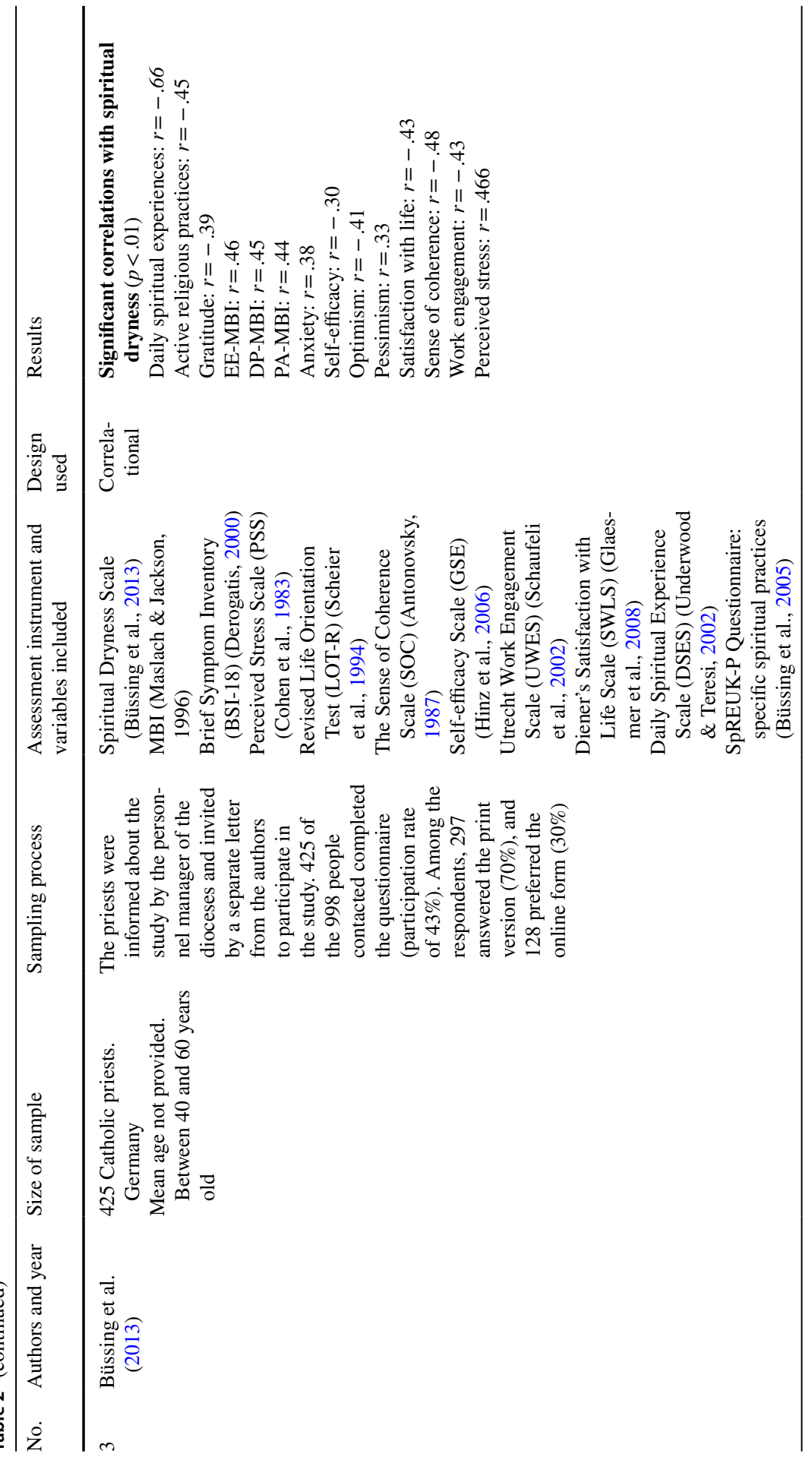




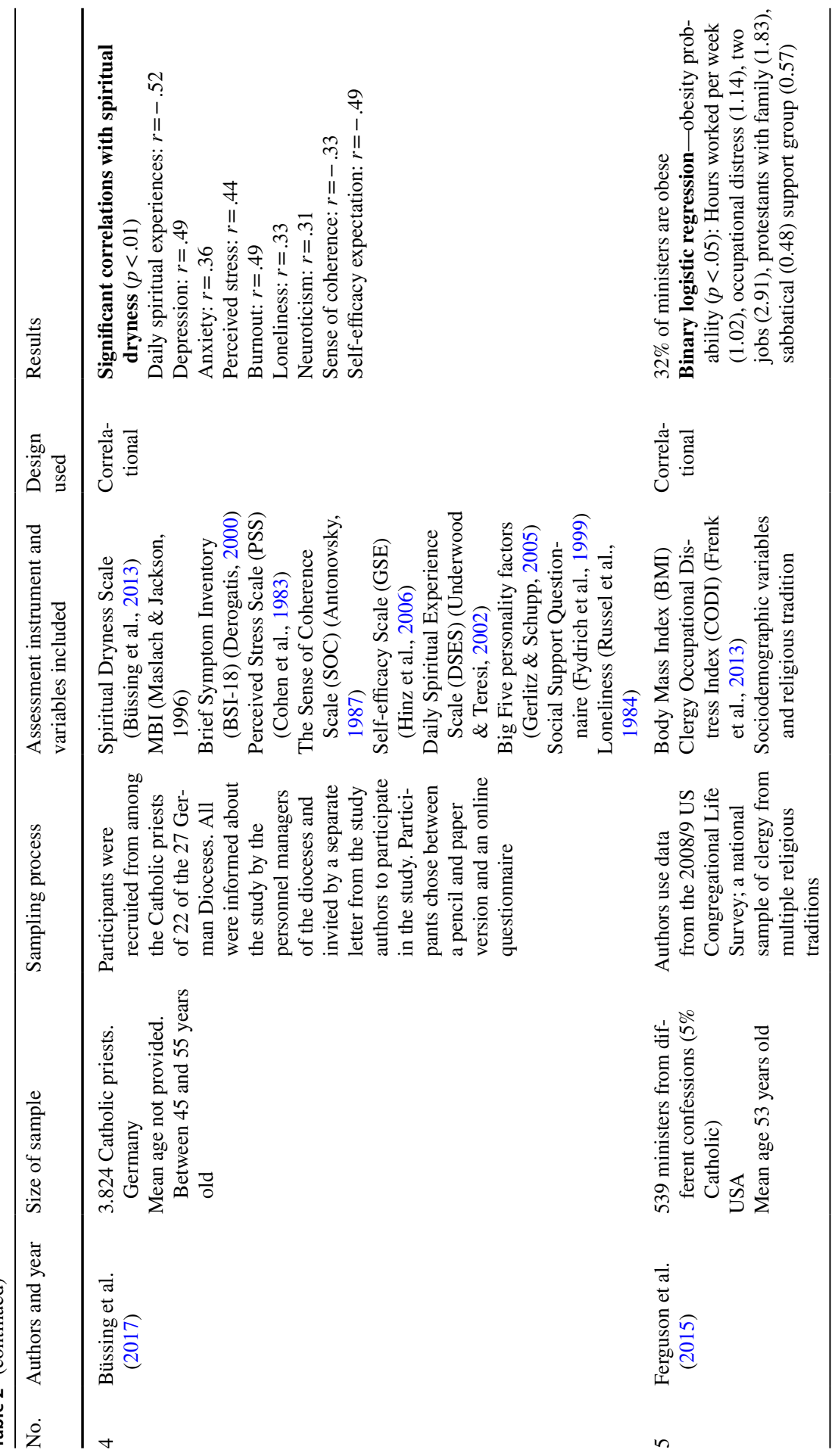




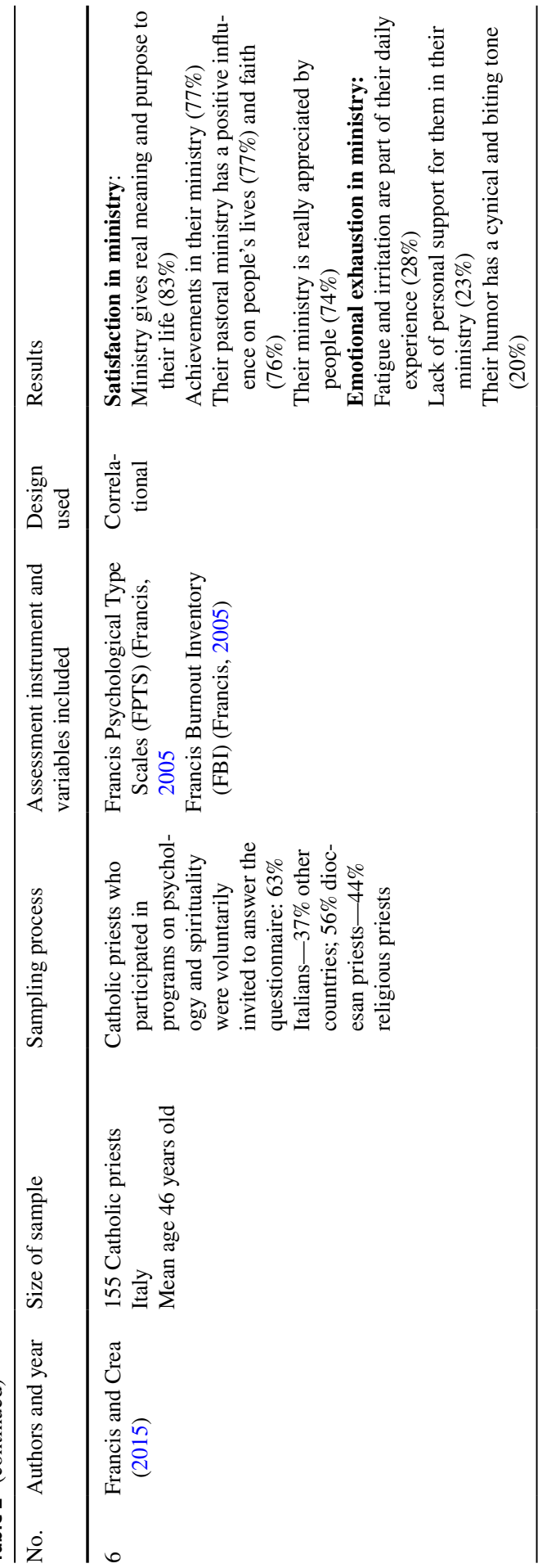




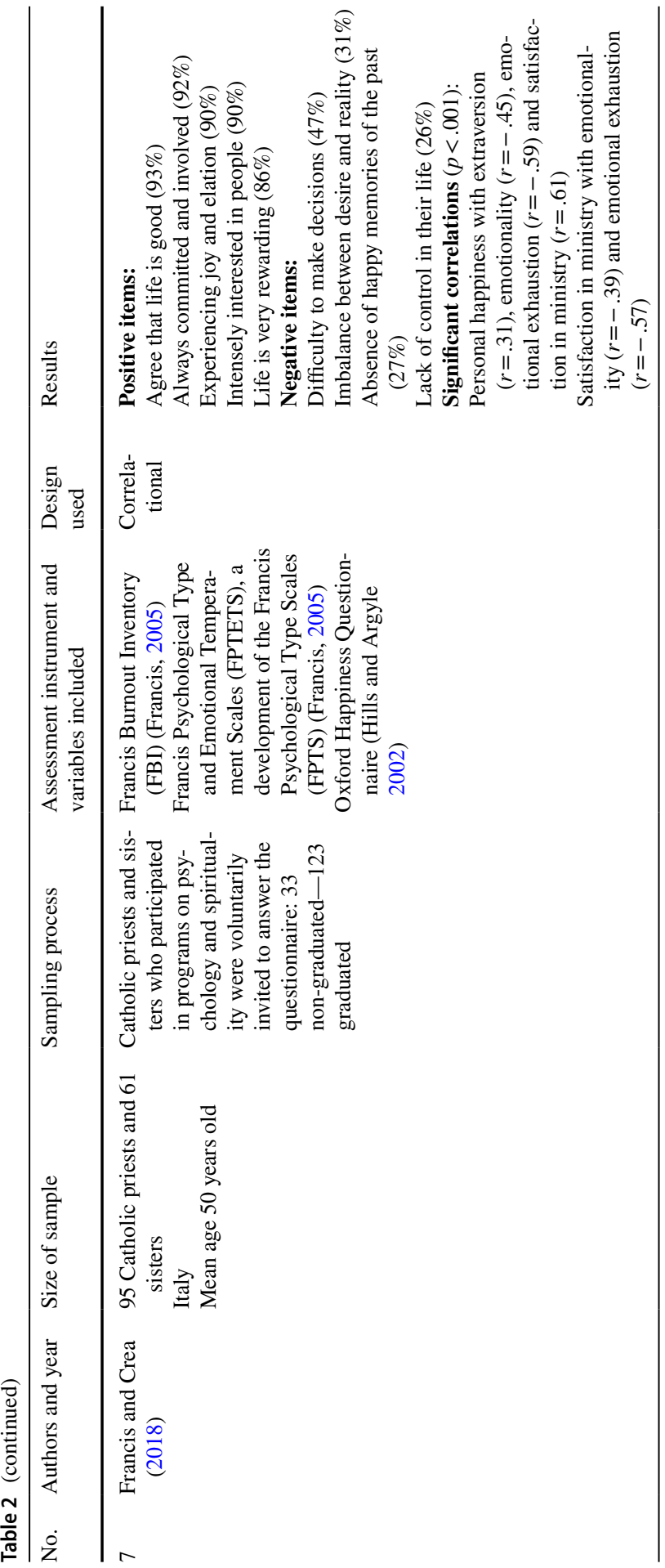




\begin{tabular}{|c|c|c|}
\hline & 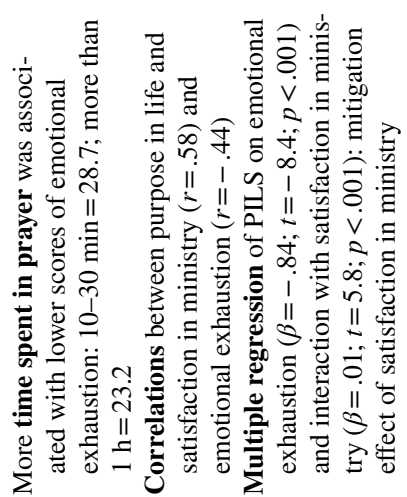 & 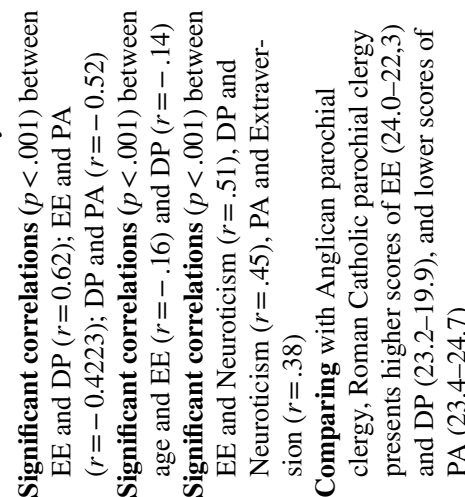 \\
\hline 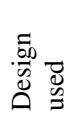 & 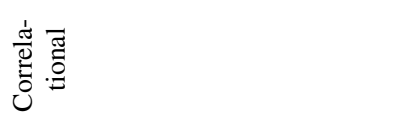 & 它 \\
\hline 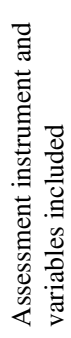 & 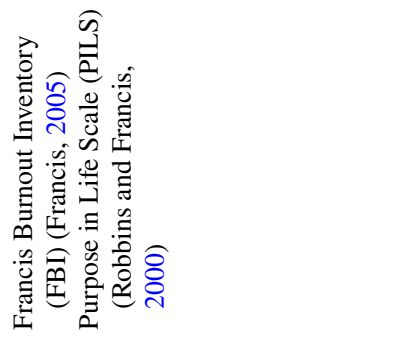 & 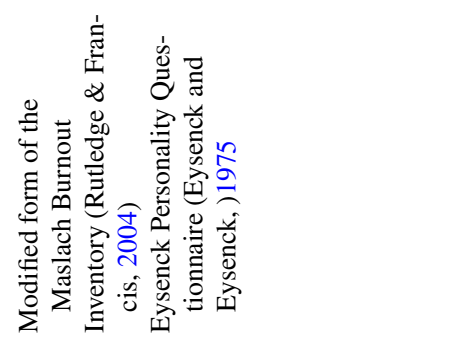 \\
\hline 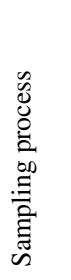 & 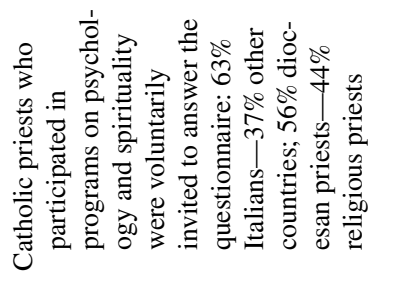 & 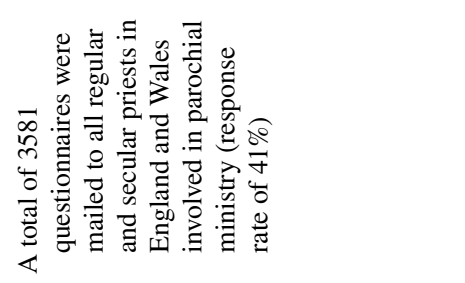 \\
\hline 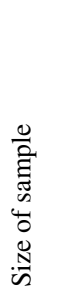 & 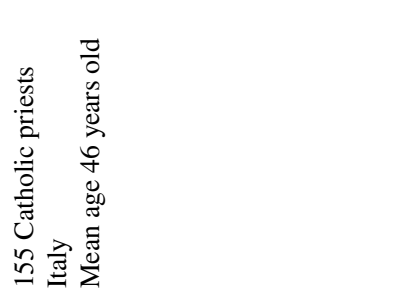 & 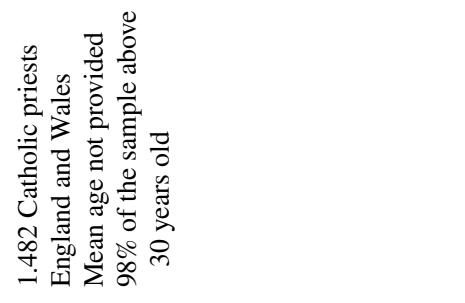 \\
\hline 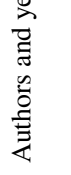 & 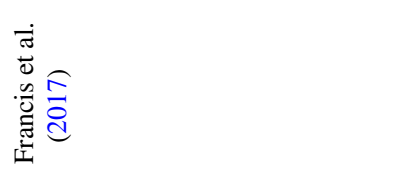 & 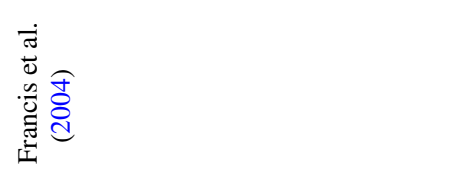 \\
\hline$\dot{z}$ & & \\
\hline
\end{tabular}




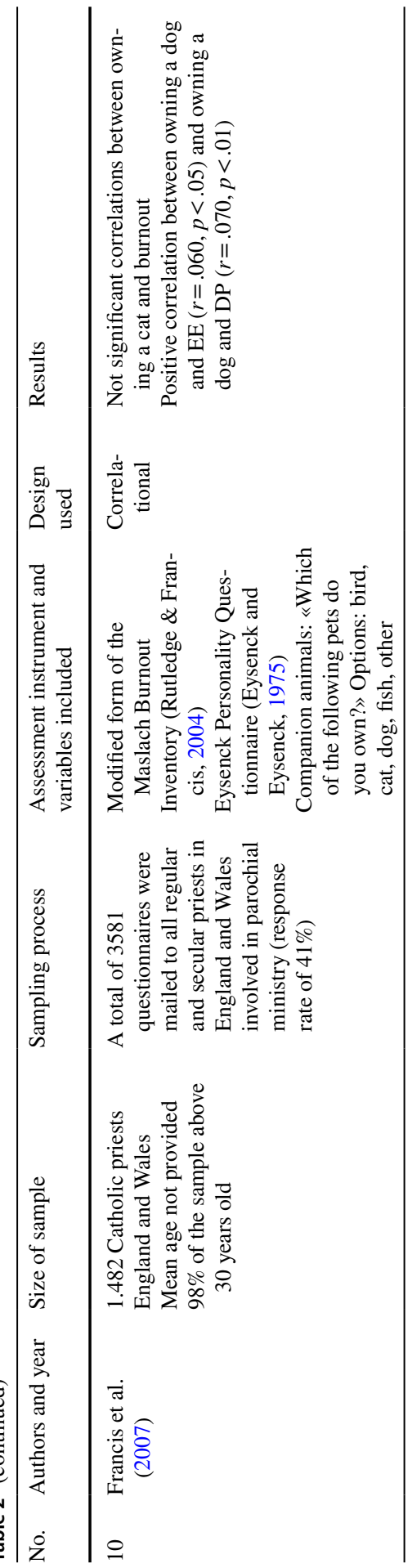




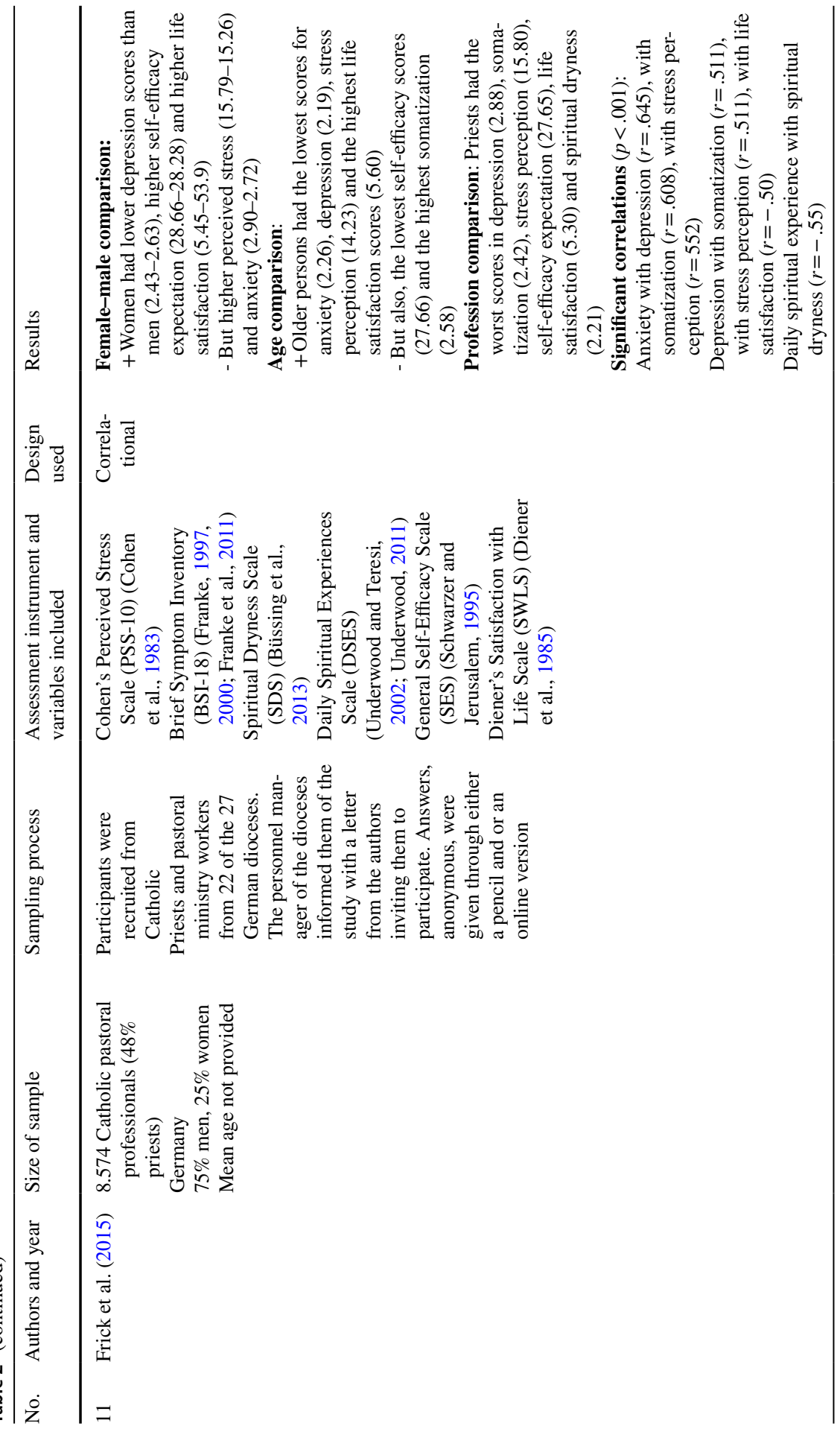




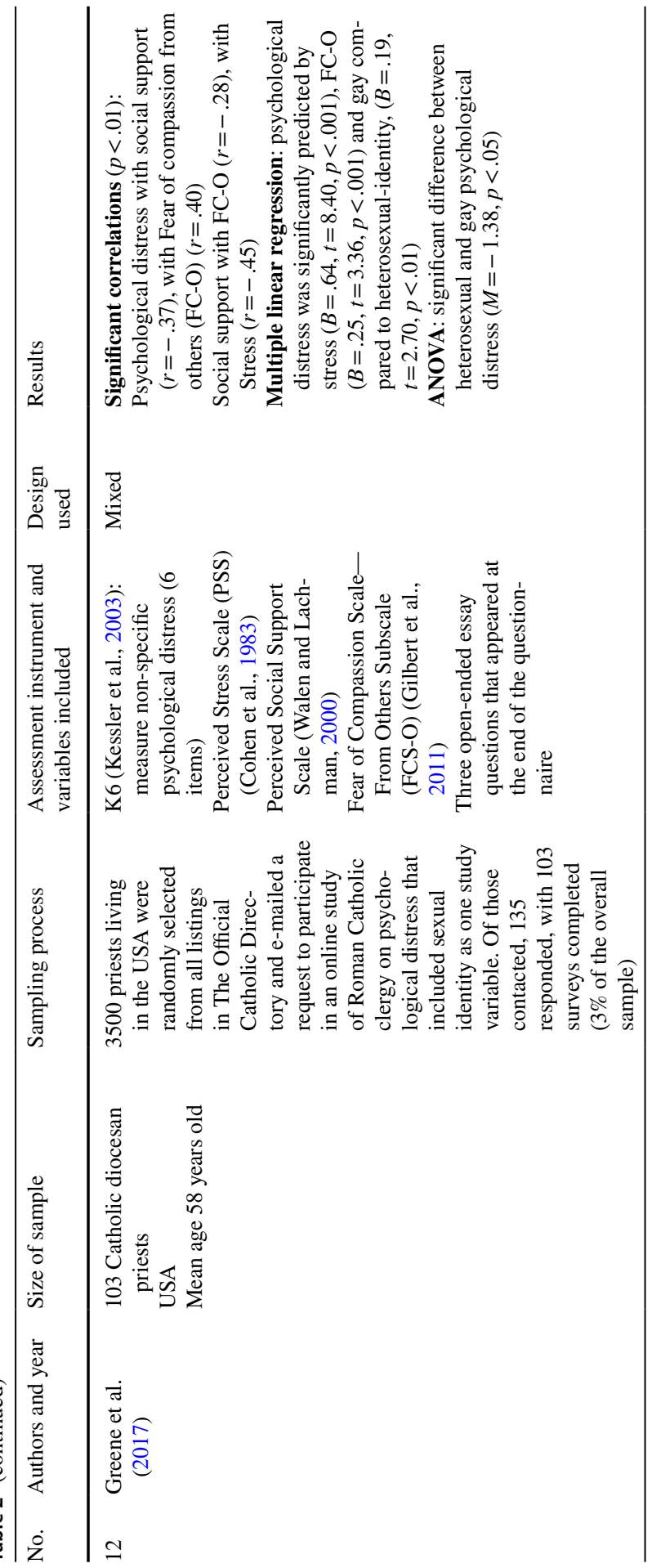




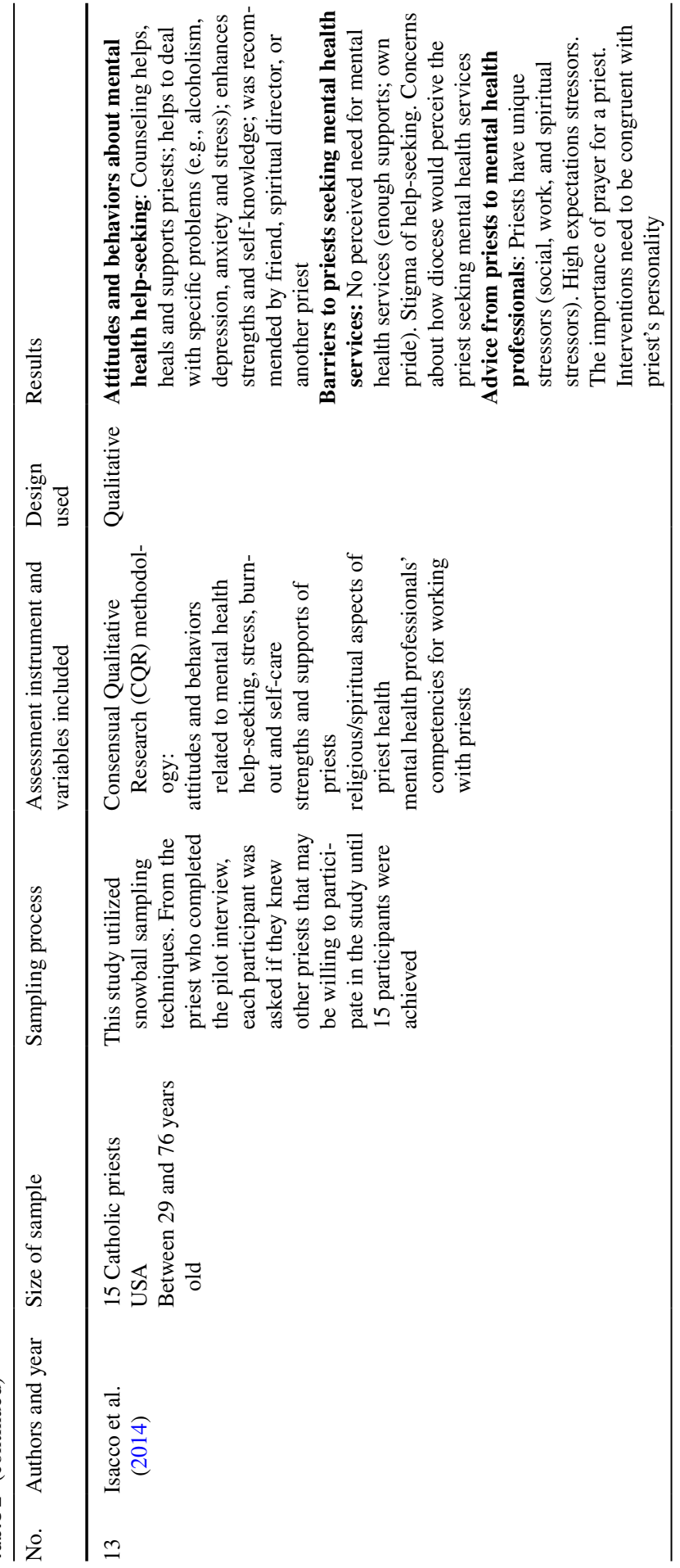




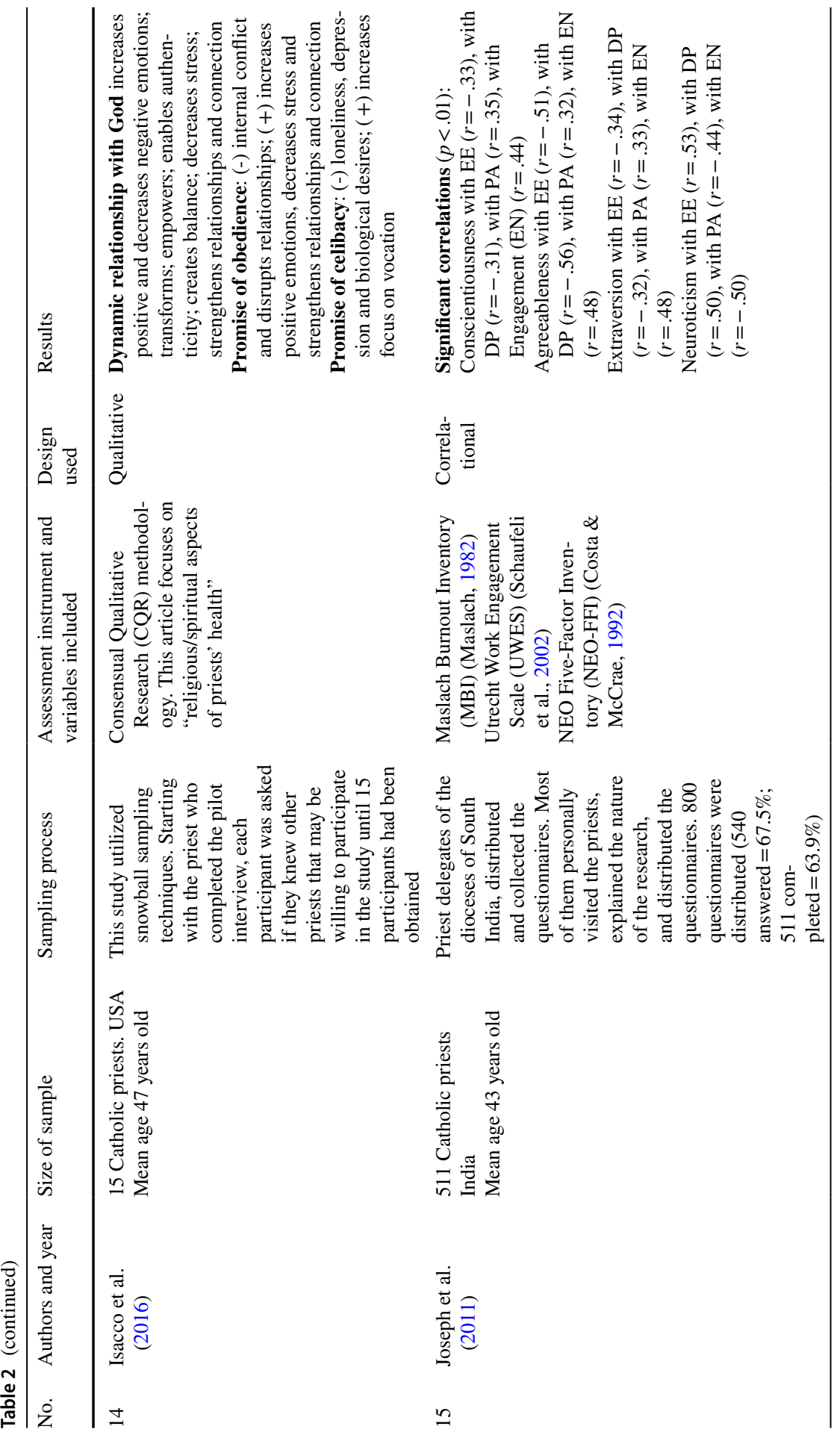




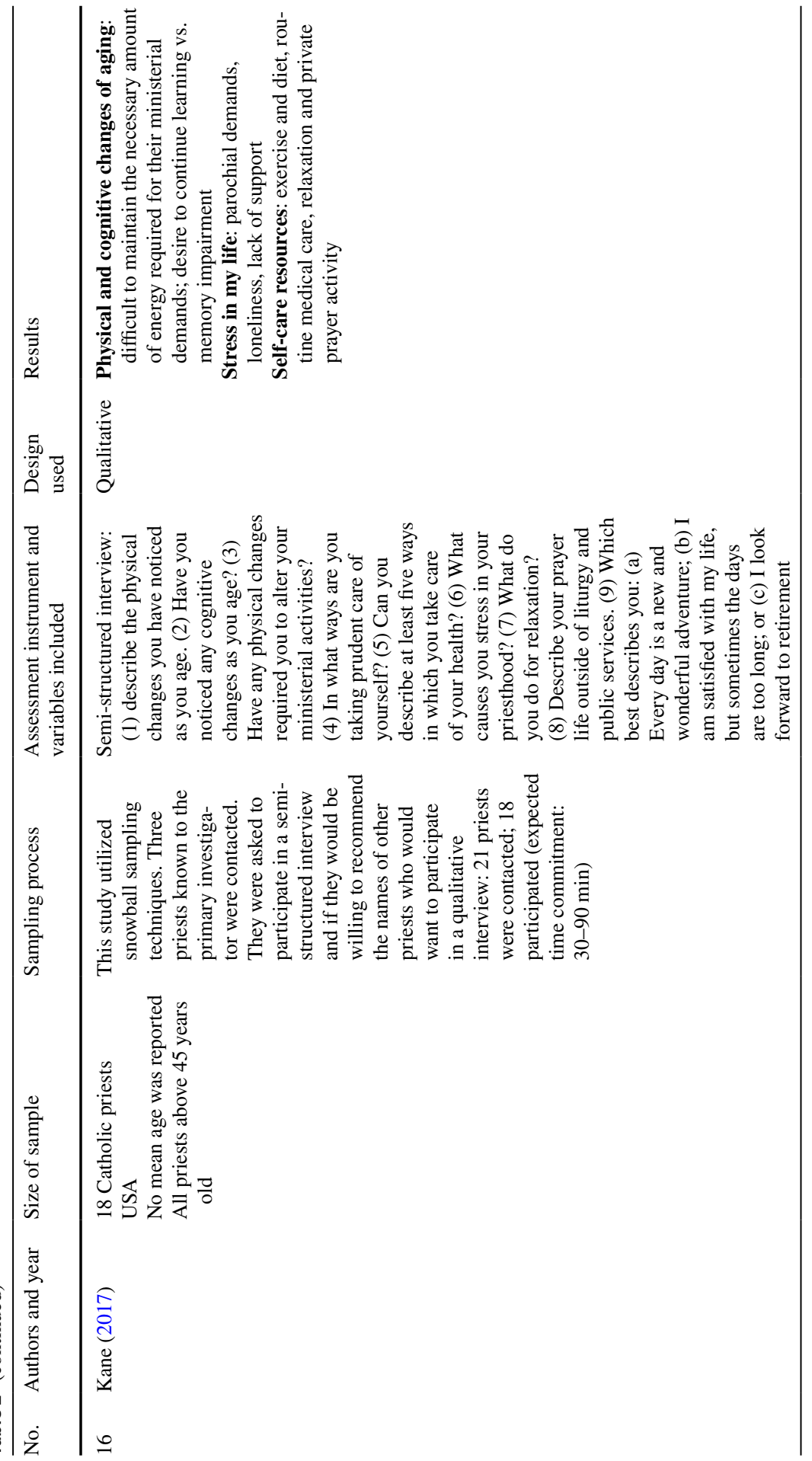




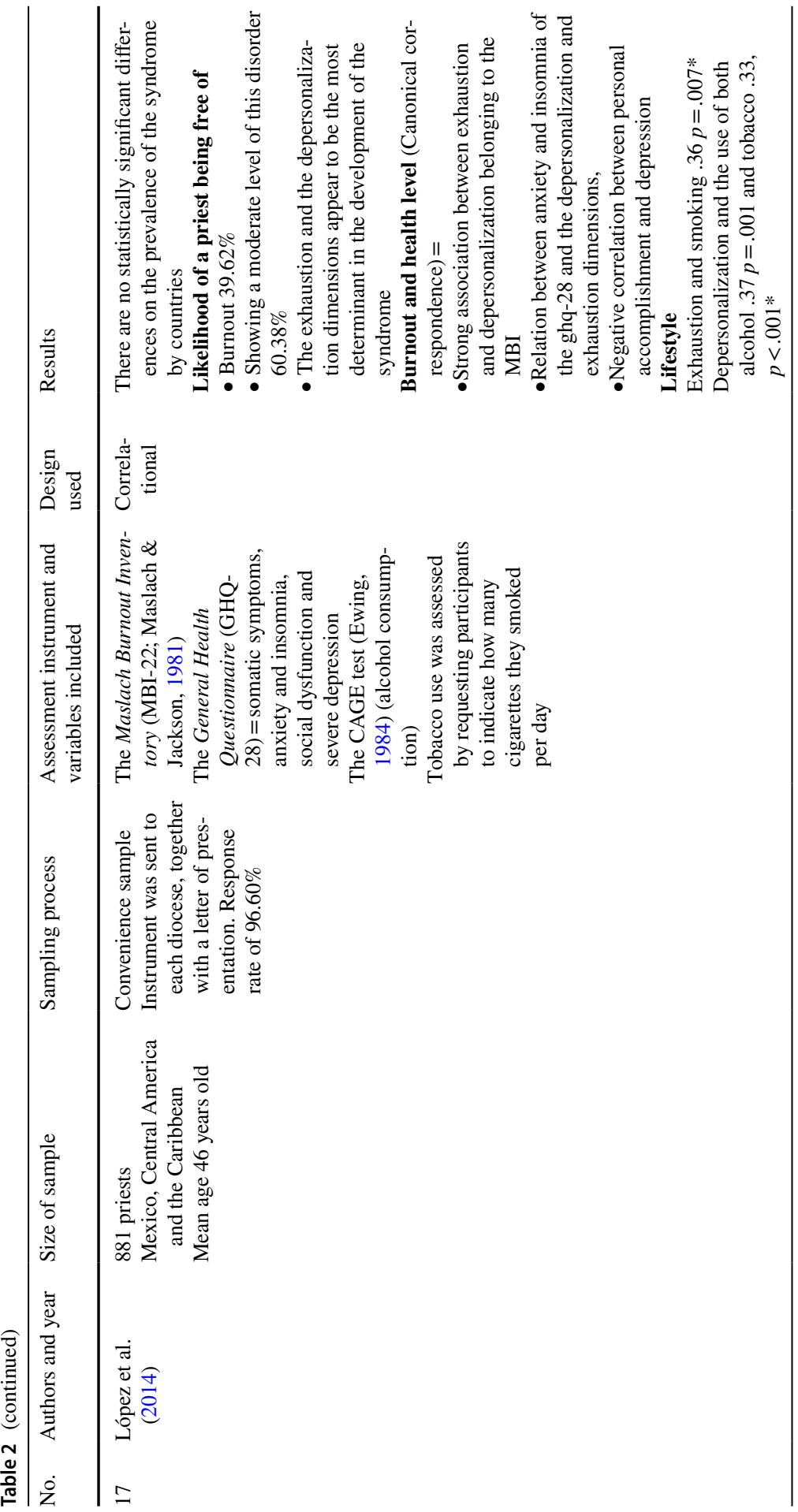




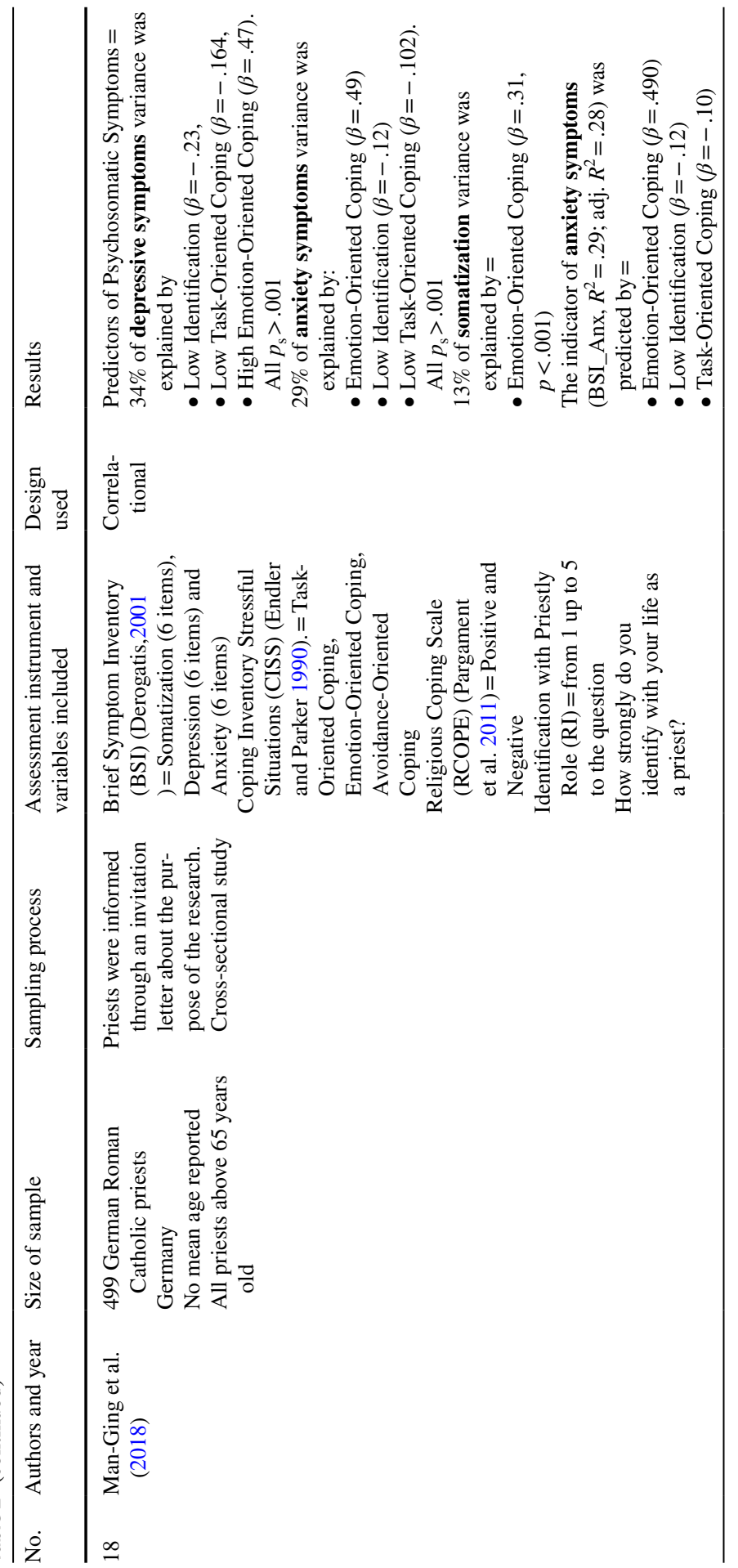




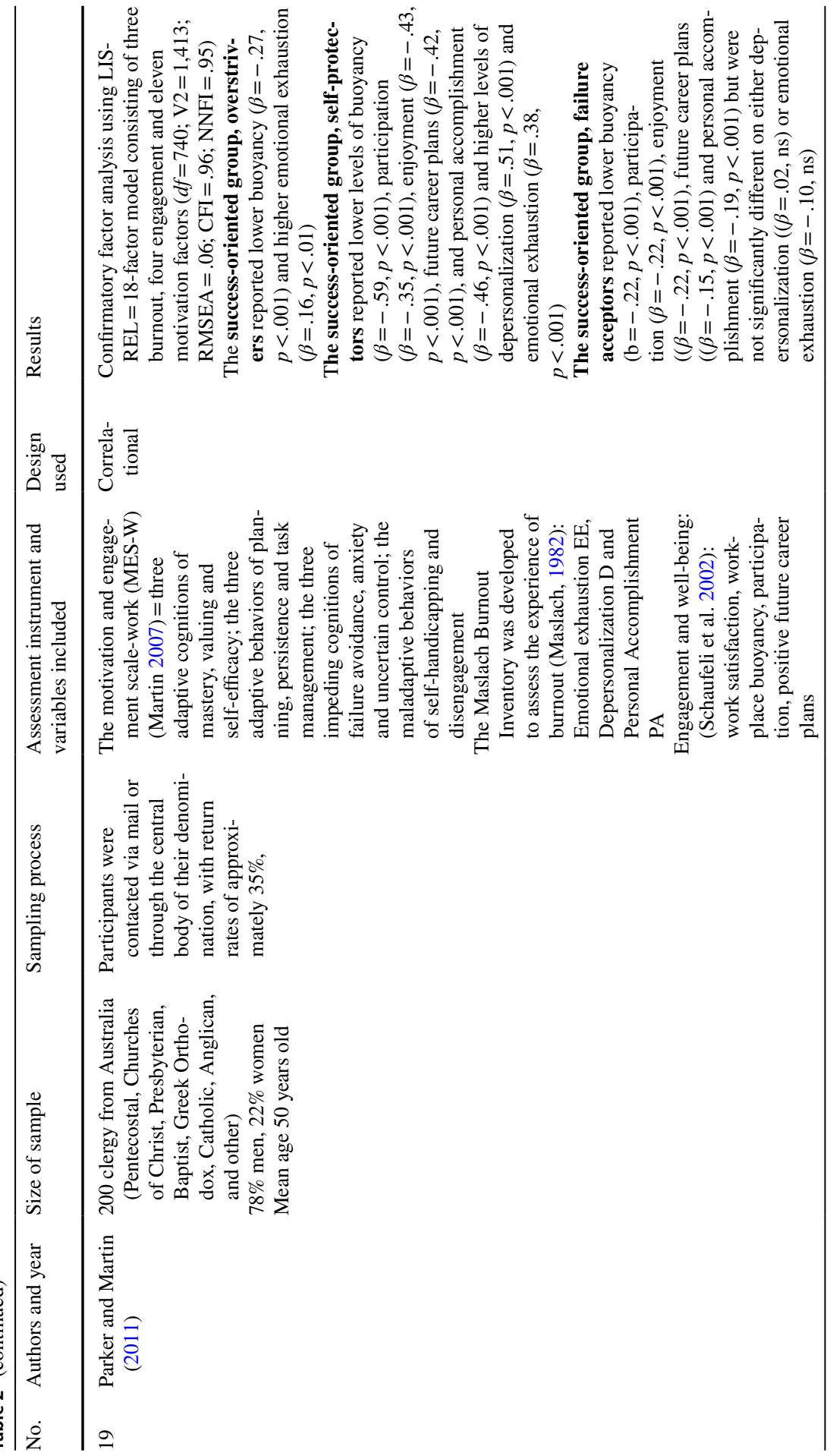




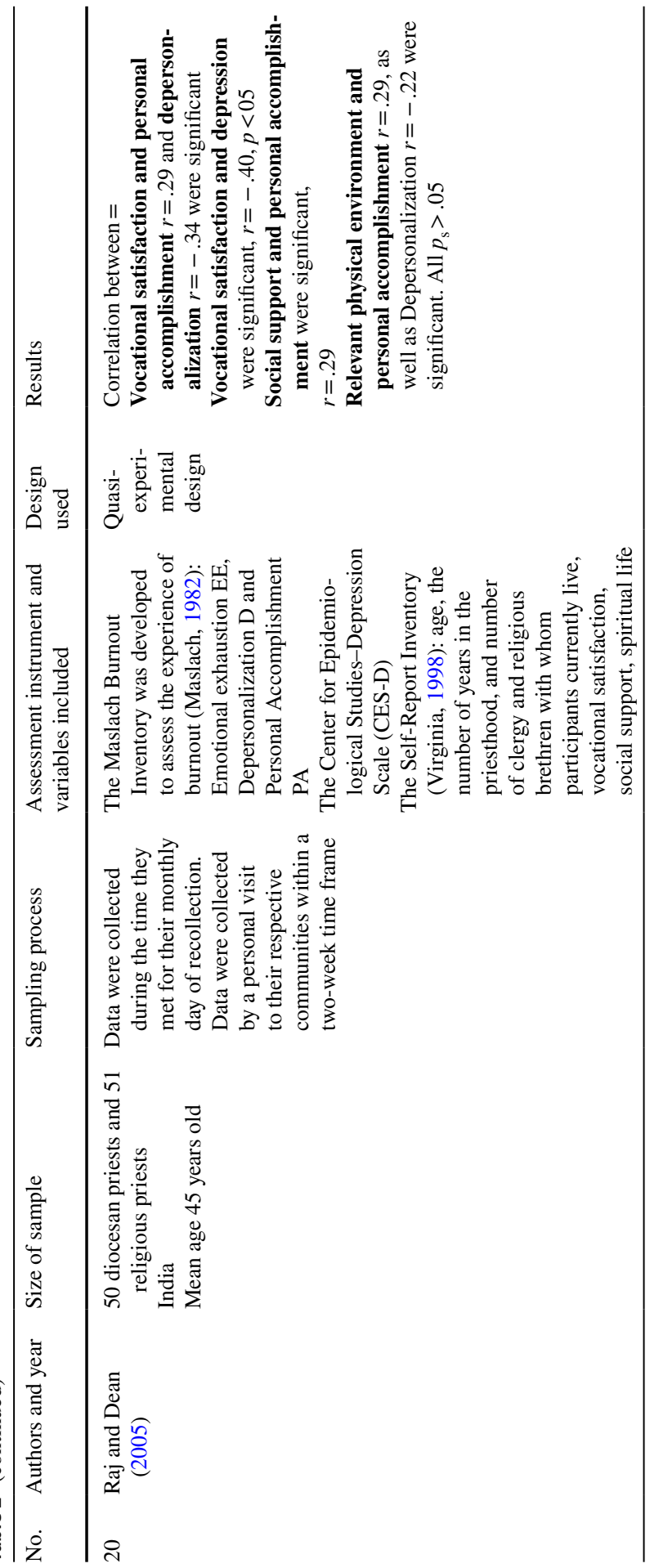




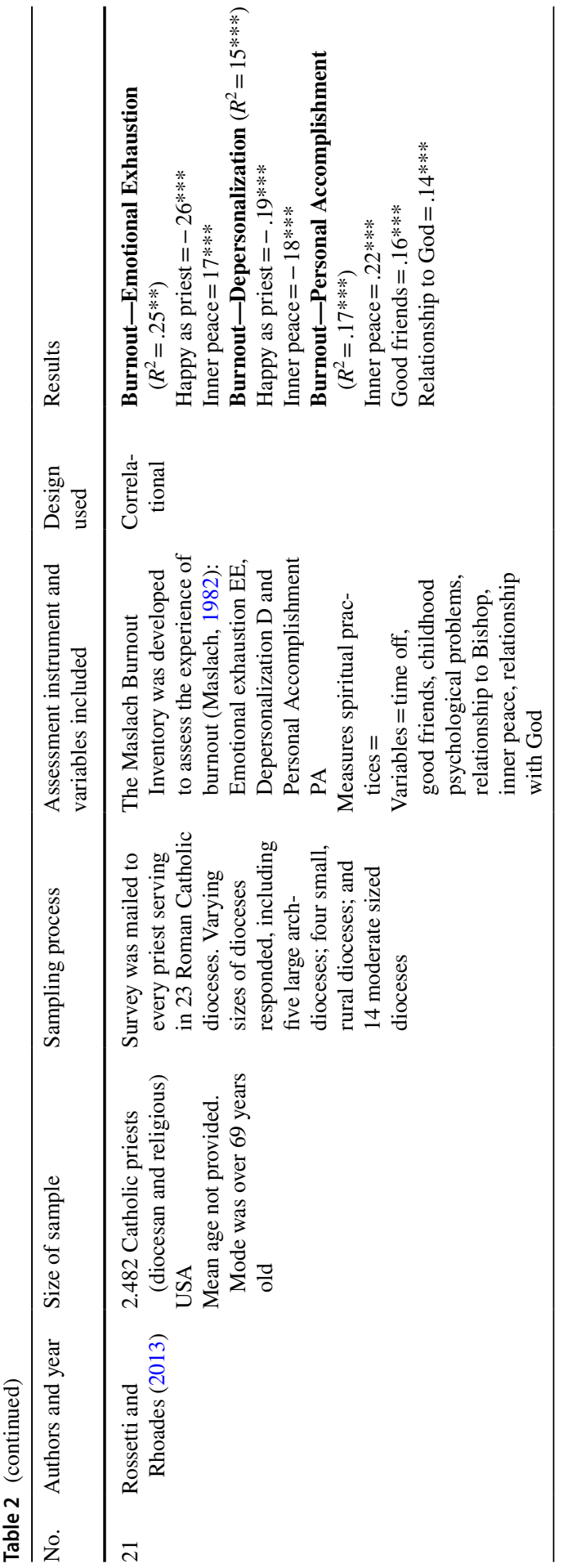




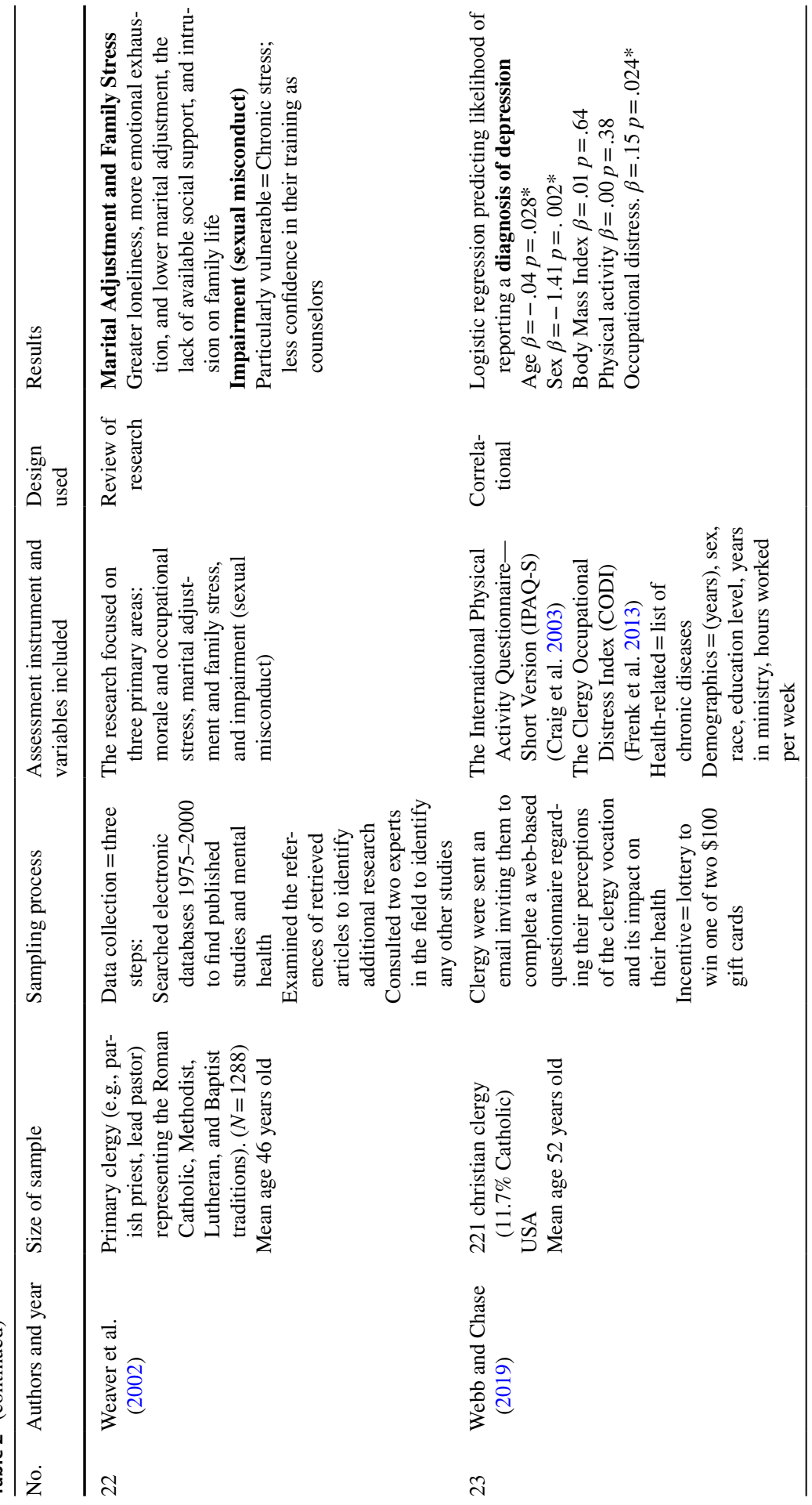




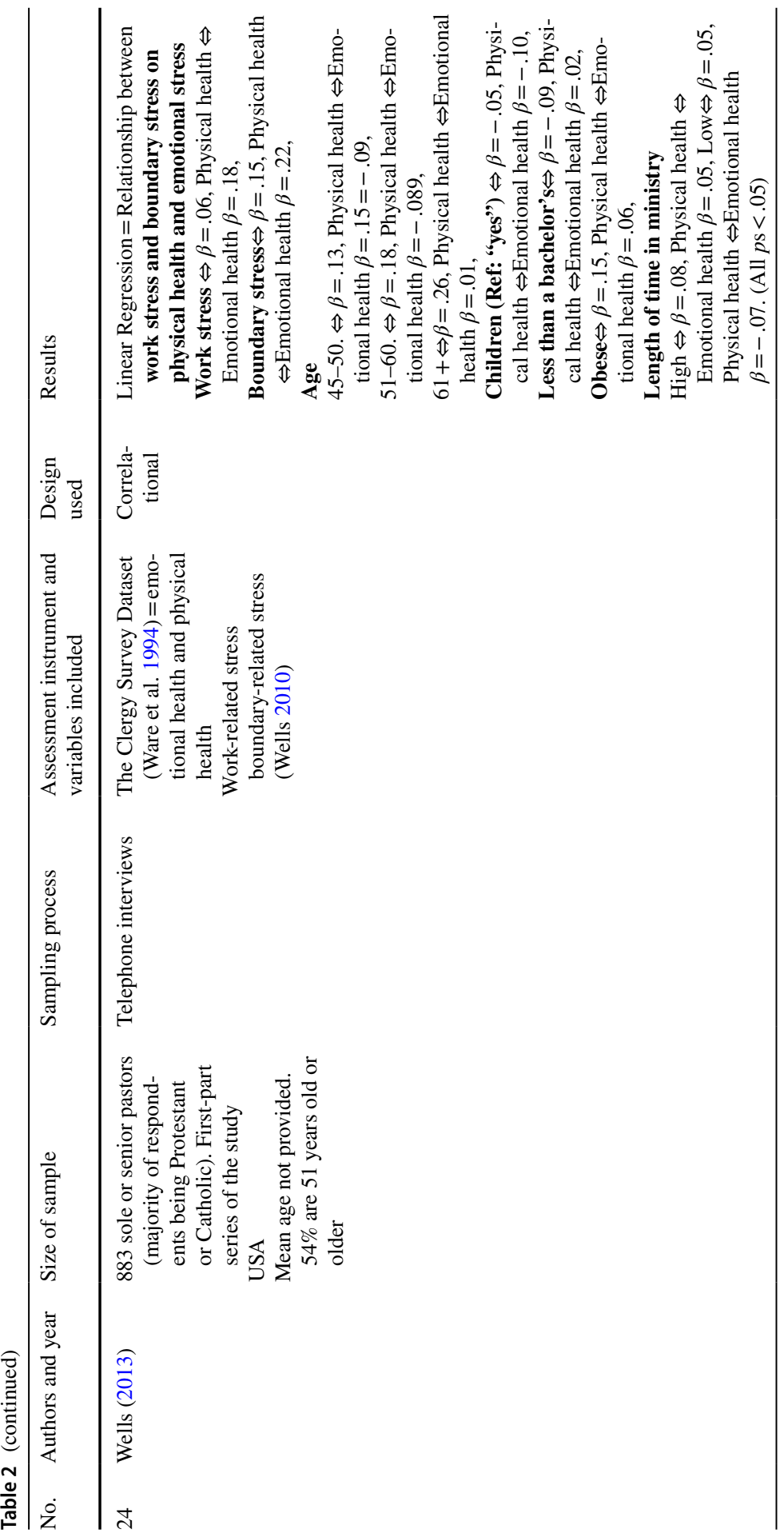




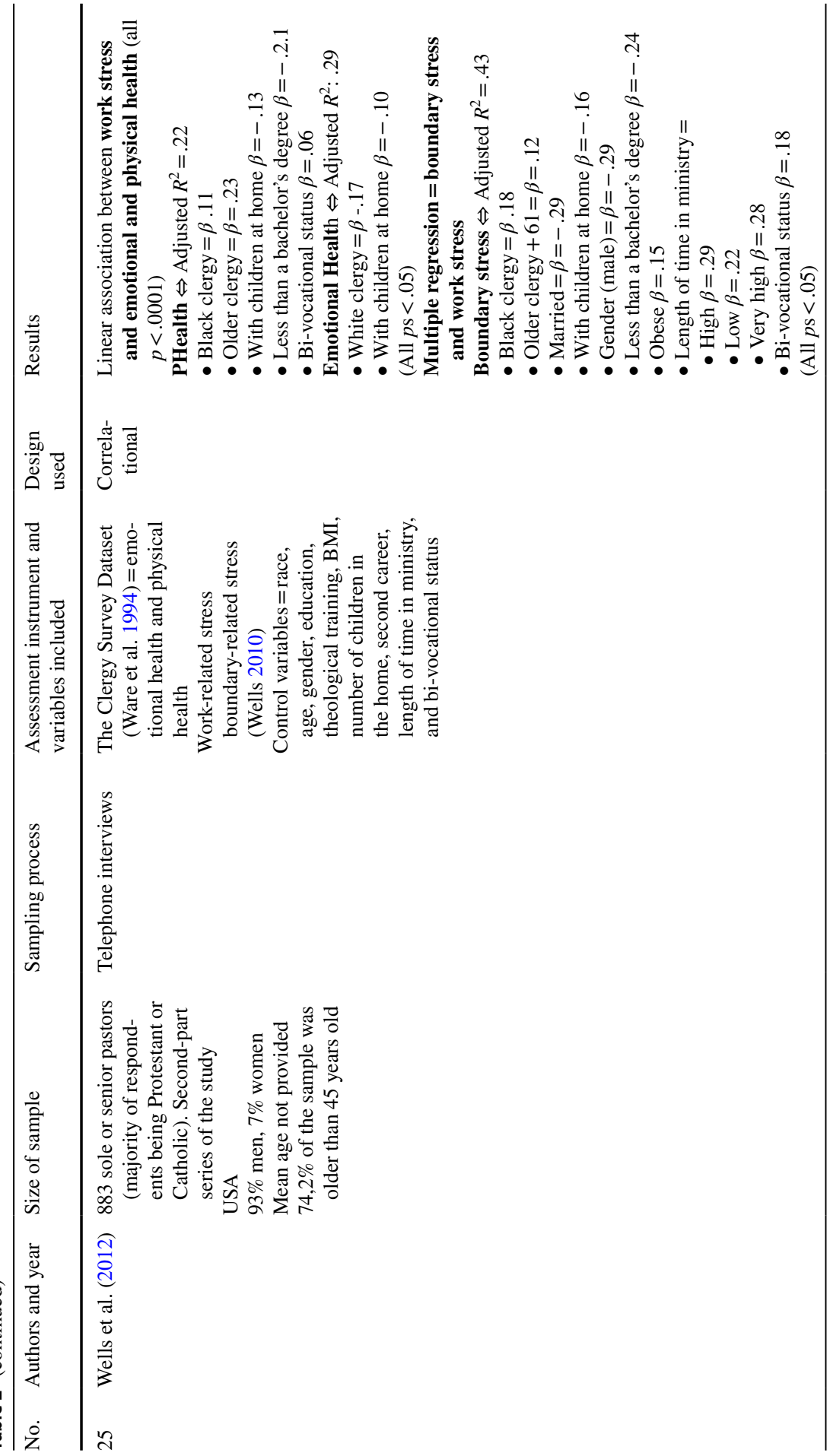




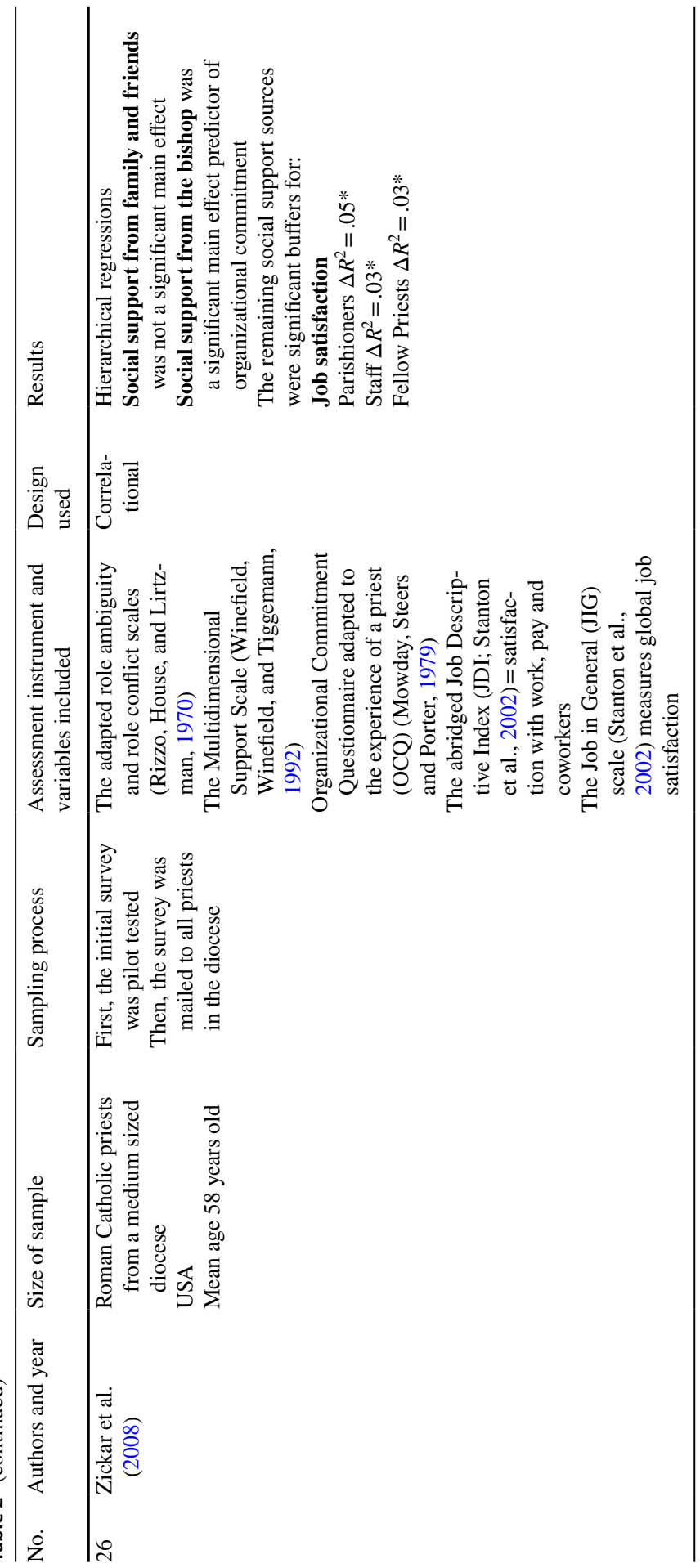


is associated with the ability to develop internal strategies for coping with stressful situations and life challenges; in other words, the older the priest, the more (and better) strategies he employs (Büssing et al., 2017). Similar results were reported also by Raj and Dean (2005), who found that the feelings of emotional exhaustion experienced by priests who had been in the priesthood for 10 years or less were stronger and more intense than those experienced by their older counterparts.

In another study conducted in England and Wales, 1,468 questionnaires were completed by Catholic priests (both religious and diocesan). The measurement instruments were the Maslach Burnout Inventory (modified form) and the Eysenck Personality Questionnaire. The results revealed that priests aged between 40 and 49 scored higher for emotional exhaustion and depersonalization, while scores for personal accomplishment hardly varied at all across the different age groups. From age 60 onwards, scores for emotional exhaustion and depersonalization decreased. One possible explanation is that older clergy have learned to "make peace" with their job and have developed strategies for identifying the signals of impending burnout in order to take steps to avoid it (Francis et al., 2004). Similar results were found by Frick et al. (2015) and Webb and Chase (2019), who reported that older priests, who have to cope with fewer external stressors, have greater life satisfaction and better perceived self-efficacy.

Nevertheless, older priests do have to cope with certain age-related stressors: the need to take better care of their health as it gradually deteriorates (which generates anxiety, particularly among those who live alone), changes in residence (some move to care homes), a reduction in their social and ecclesiastical relevance (they no longer occupy positions of responsibility), the loss of loved ones and more free time, among others. Moreover, due to the lack of priests, older clergy often continue to perform different tasks and duties until a very advanced age. Faced with this situation, elderly priests need both effective coping strategies and acceptance and flexibility in order to learn to live with their new situation without losing sight of their own personal goals (Man-Ging et al., 2018).

A study conducted with 499 German clergy aged 65 and over (the majority diocesan priests) found that most had a good coping style and were less at risk of anxiety, depression and psychosomatic symptoms than those with avoidant behavior and negative emotionality. Similarly, identifying with the role of priest and with the organization, and having a strong spiritual life were found to be important protective factors (Man-Ging et al., 2018).

In another study, Kane (2017) held semi-structured interviews with 18 retired Catholic priests. The results reported are consistent with those outlined above, namely that older priests were satisfied with their life and ministry, were beginning to experience more health-related problems and, although they were slowing down, were nevertheless still keen to continue learning. However, due to the current scarcity of priests, many had no choice but to continue collaborating very actively in the pastoral activities of the diocese and felt there was a lack of support from the hierarchy and from parishioners, which resulted in loneliness. Respondents continued with their self-care routines as a good preventive system and protective factor. This included physical exercise, a healthy diet, routine medical care, finding time for private prayer and engaging in relaxation exercises. 
Alongside age, another variable is working environment: rural or urban. One study reported that priests working in urban areas feel a greater sense of personal accomplishment than those working in rural environments (Raj \& Dean, 2005).

Sociodemographic variables of the studies included in this review may be consulted in Table 3 .

\section{Psychological Factors and Coping Styles}

Following Scopus review suggestions, in this section we are analyzing the relationships between important factors on stress among priests. The personality characteristics that lead to burnout are mainly found in idealists, perfectionists and compulsives (Raj \& Dean, 2005). In the studies analyzed, high scores for extraversion correlated with low levels of emotional exhaustion and depersonalization and high levels of personal accomplishment, whereas high scores for neuroticism correlated with high levels of emotional exhaustion and depersonalization and weak feelings of personal accomplishment (which in turn are linked to low expectations regarding self-efficacy). Finally, high scores for psychoticism were associated high levels of emotional exhaustion and depersonalization (Francis et al., 2004).

In a study conducted with 155 Catholic priests (63\% Italian and 37\% from other countries; $56 \%$ diocesan and $44 \%$ religious), work-related health was analyzed in relation to psychological type: extravert or introvert. The principal conclusion drawn was that introverted priests have poorer work-related psychological heath than extraverted ones. This is mainly manifested in their poor results for emotional exhaustion and satisfaction with their ministry. The priesthood seems to attract more introverts than extraverts, since $59 \%$ of participants in the study fell into this psychological type. Nevertheless, the priestly role involves a great deal of public presence and intense interpersonal demands and requires clergy to interact with people in different contexts - something which seems much more suited to an extraverted personality (Francis \& Crea, 2015). Nevertheless, introversion fosters a deeper spiritual life, which is very important to a priest.

Francis and Crea (2018) also explored the link between personality, happiness and psychological health among Italian priests $(n=95)$ and nuns $(n=61)$ (studied together in a single sample). The results support previous hypotheses: extraversion predicts high scores for happiness and satisfaction with ministry and low scores for emotional exhaustion. For its part, happiness (a concept taken from positive psychology) also serves as a predictor of psychological health (positive emotionality), although it is a concept that is constantly being redefined.

In a study carried out with 511 Indian Catholic diocesan priests, Joseph et al. (2011) linked the three subscales of burnout syndrome with personality factors in accordance with the Big Five and engagement. The results revealed significant $(p<0.01)$ positive correlations between neuroticism and emotional exhaustion $(r=0.53)$ and between neuroticism and depersonalization $(r=0.50)$, and negative correlations between neuroticism and personal accomplishment $(r=-0.44)$ and between neuroticism and engagement $(r=-0.50)$. In contrast, extraversion correlated positively with personal accomplishment $(r=0.33)$ and engagement 


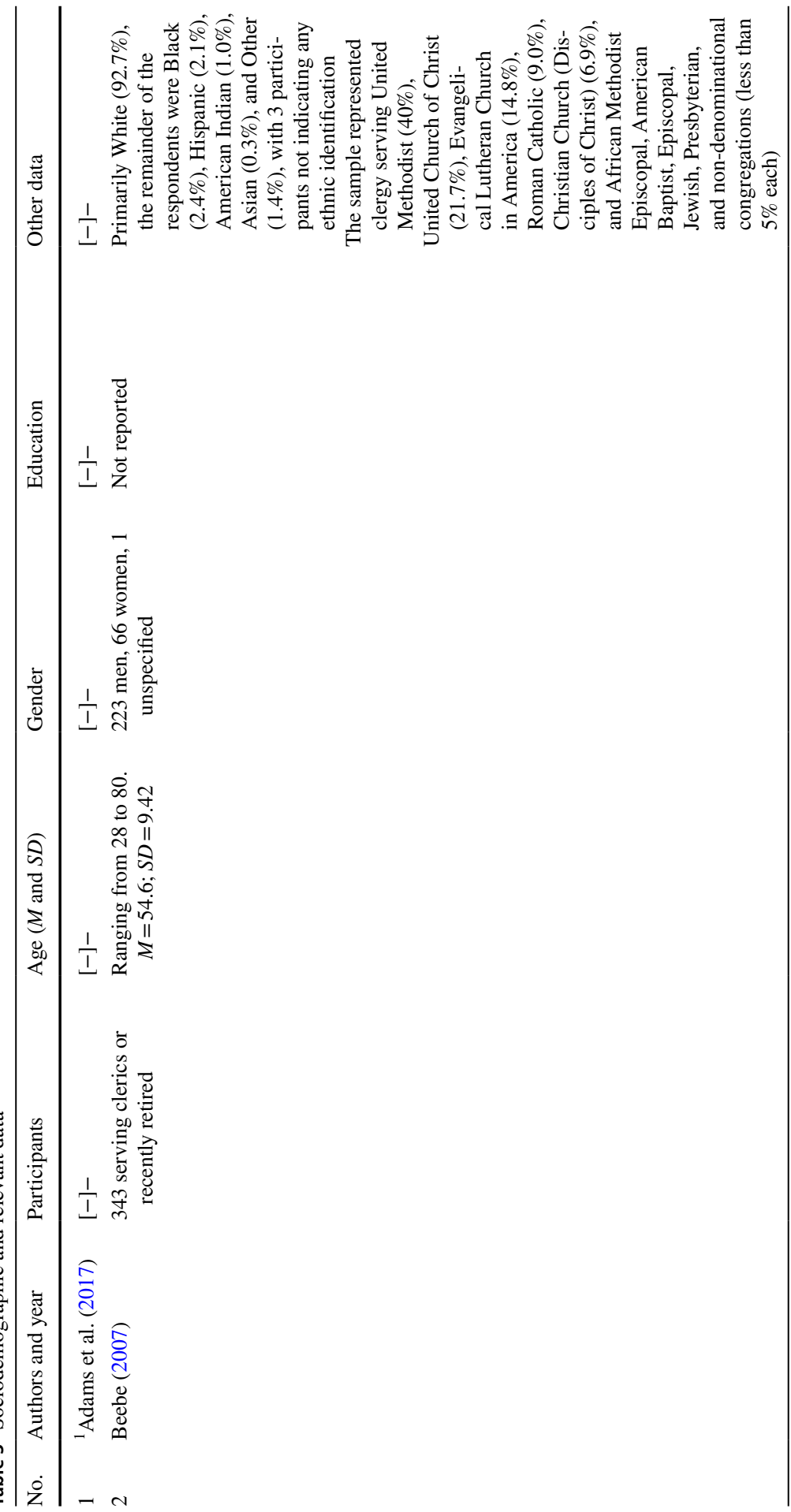




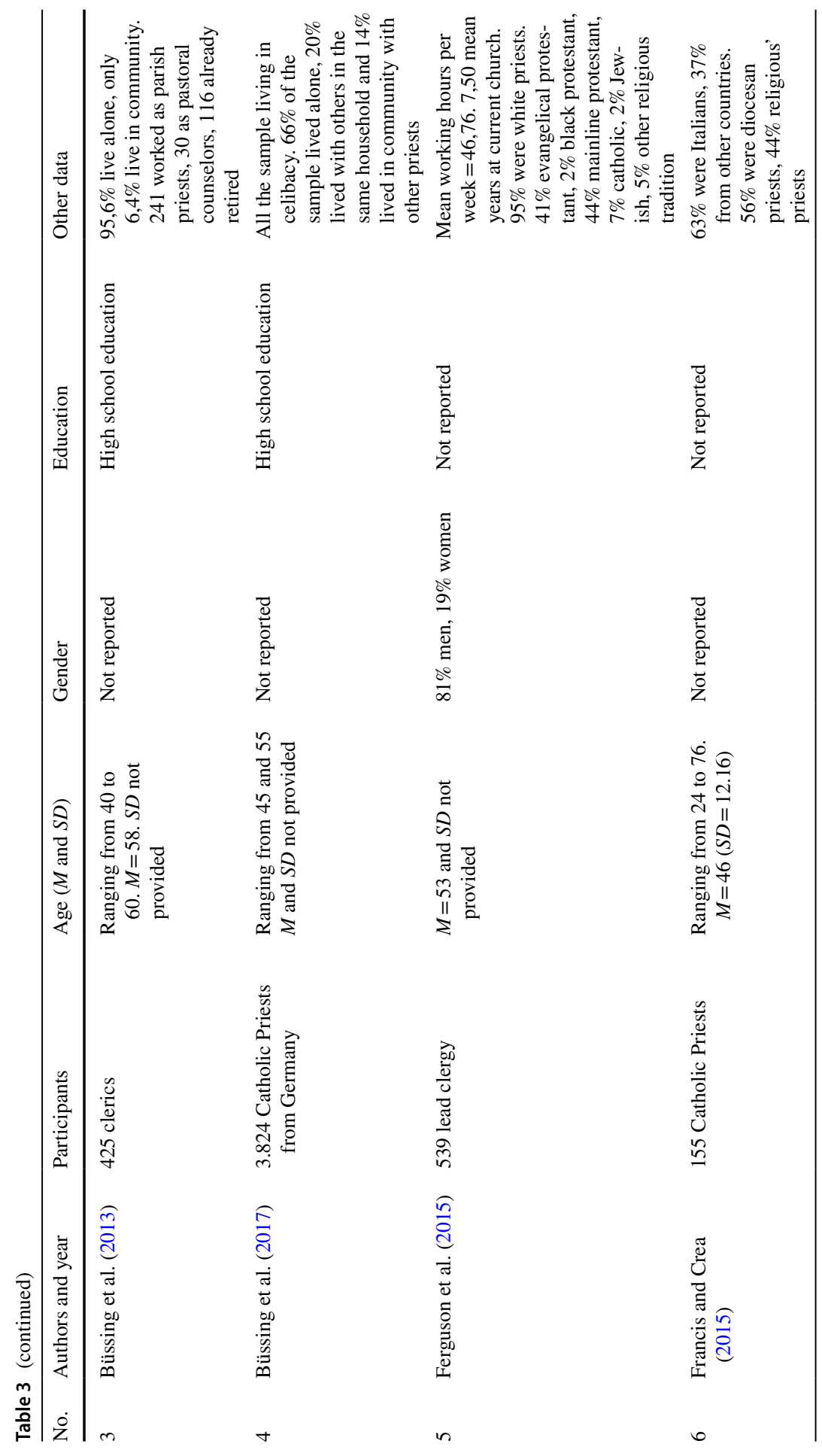



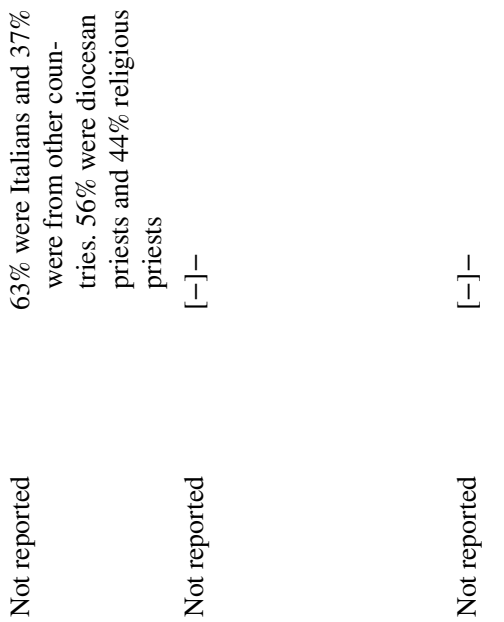

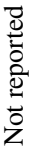

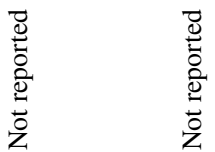

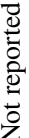

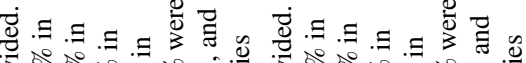

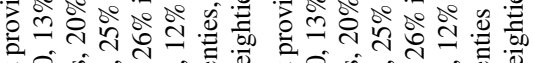

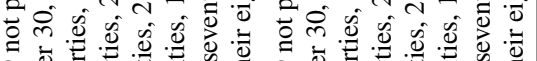

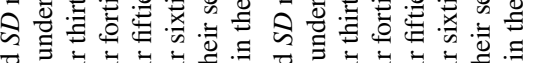

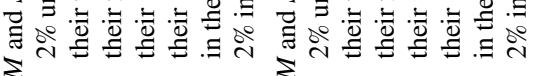

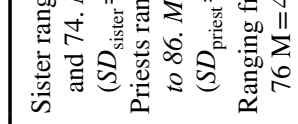
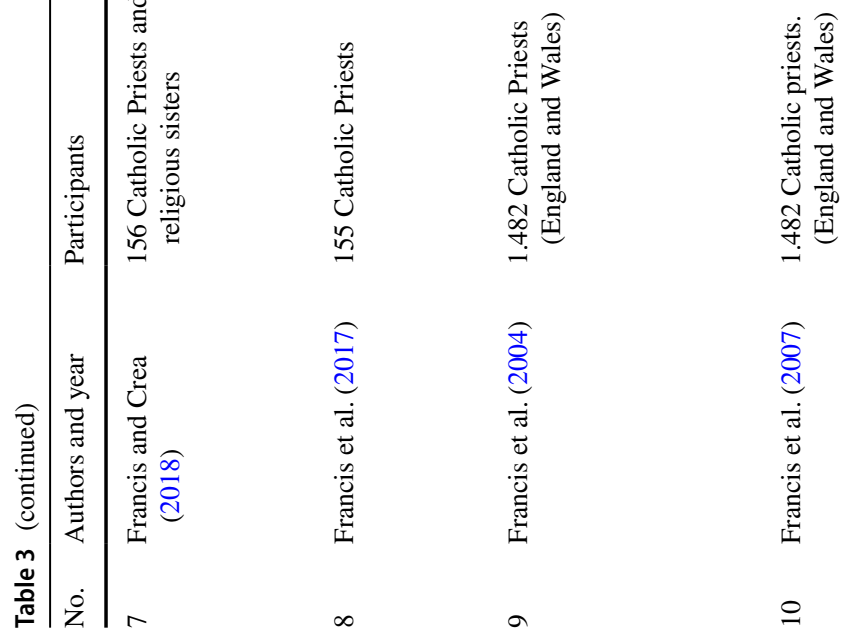


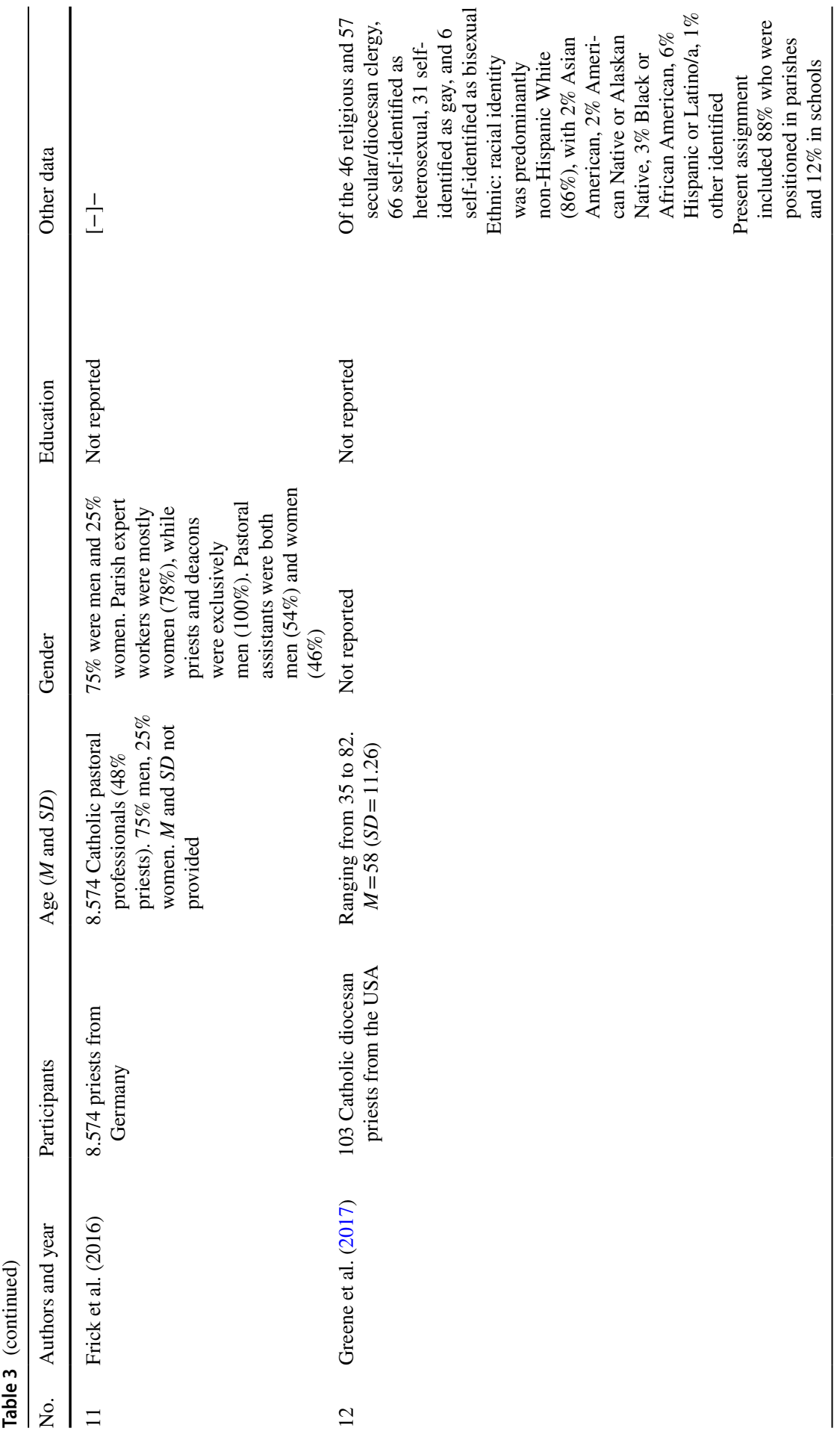




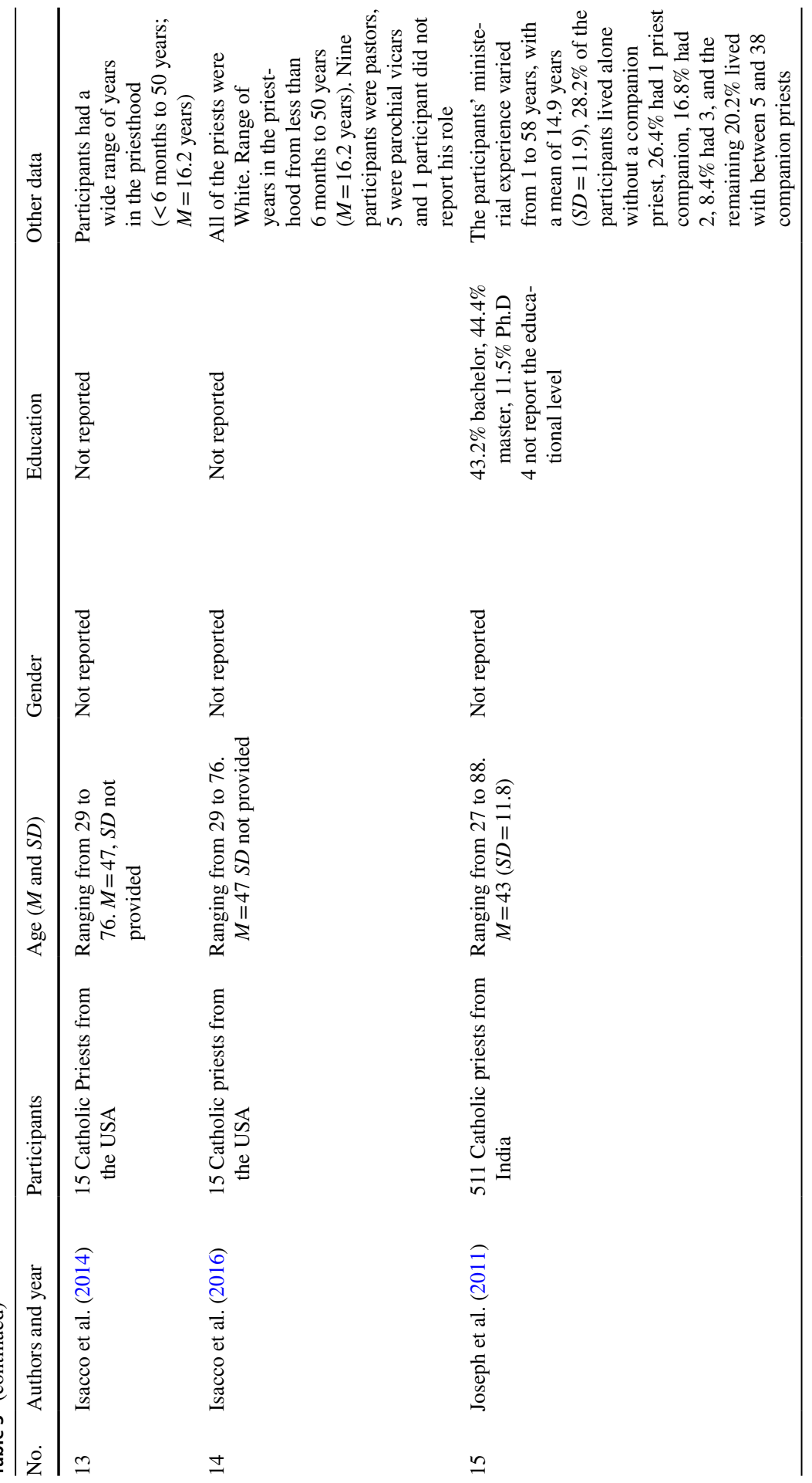




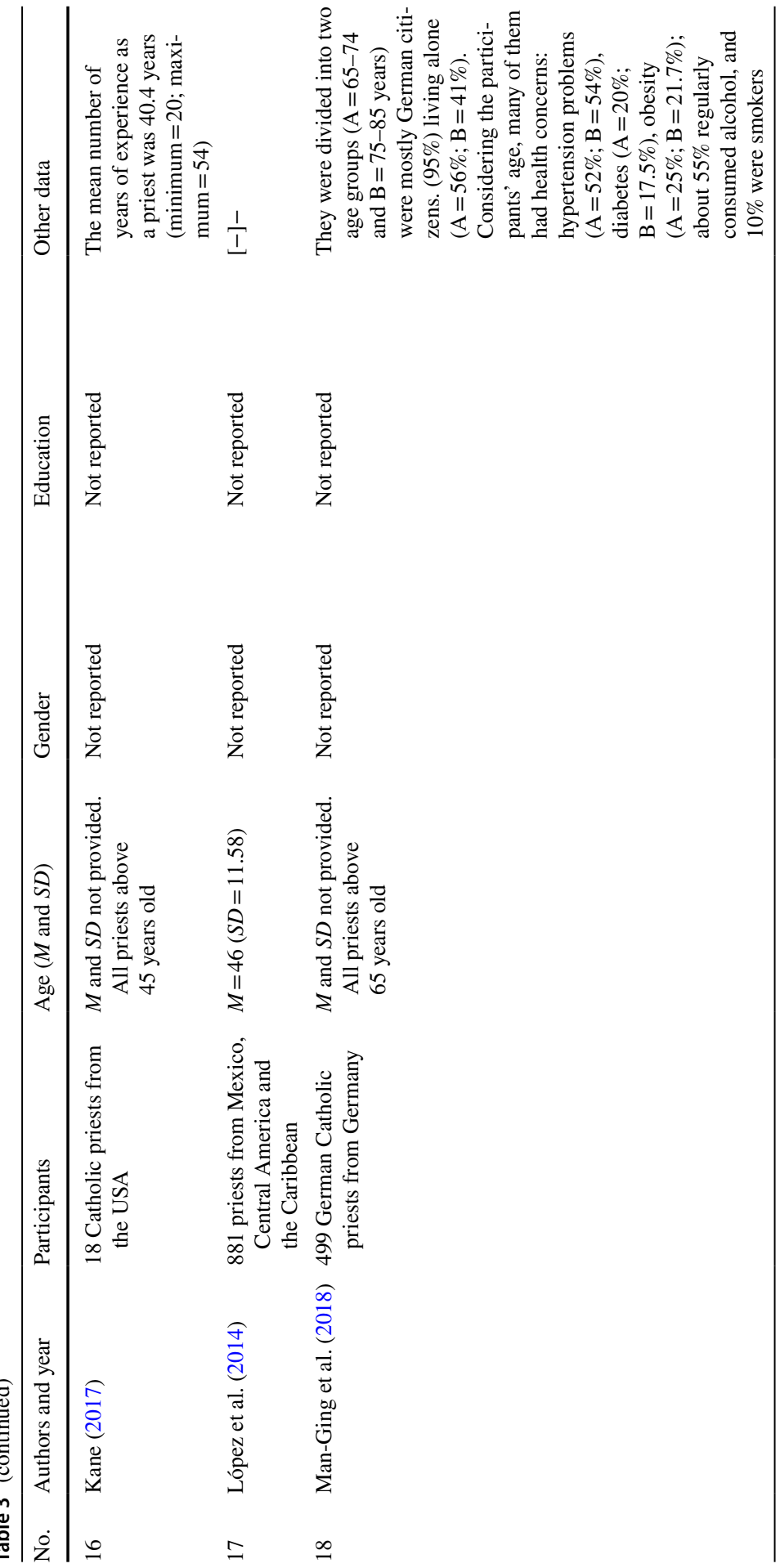




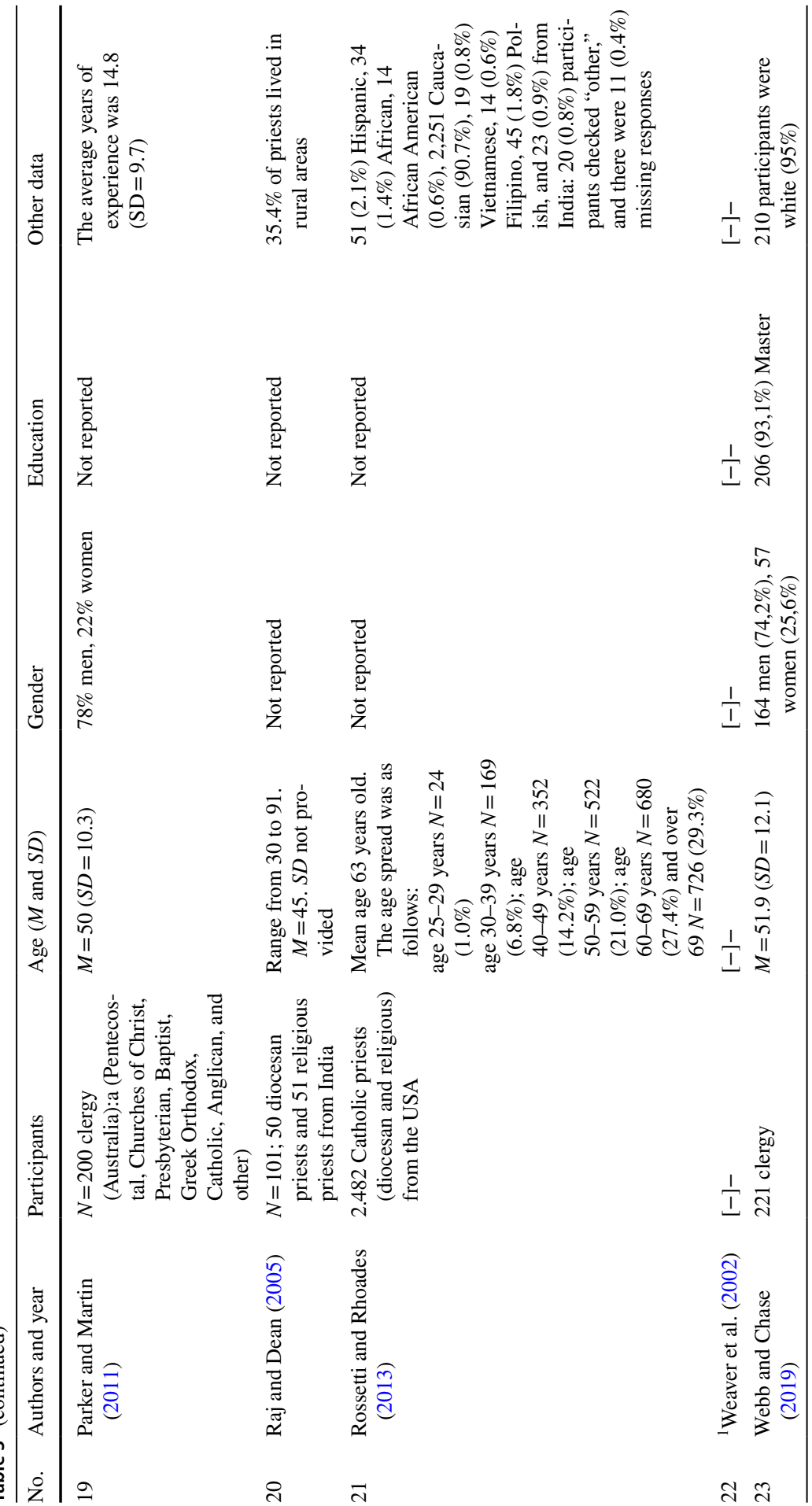




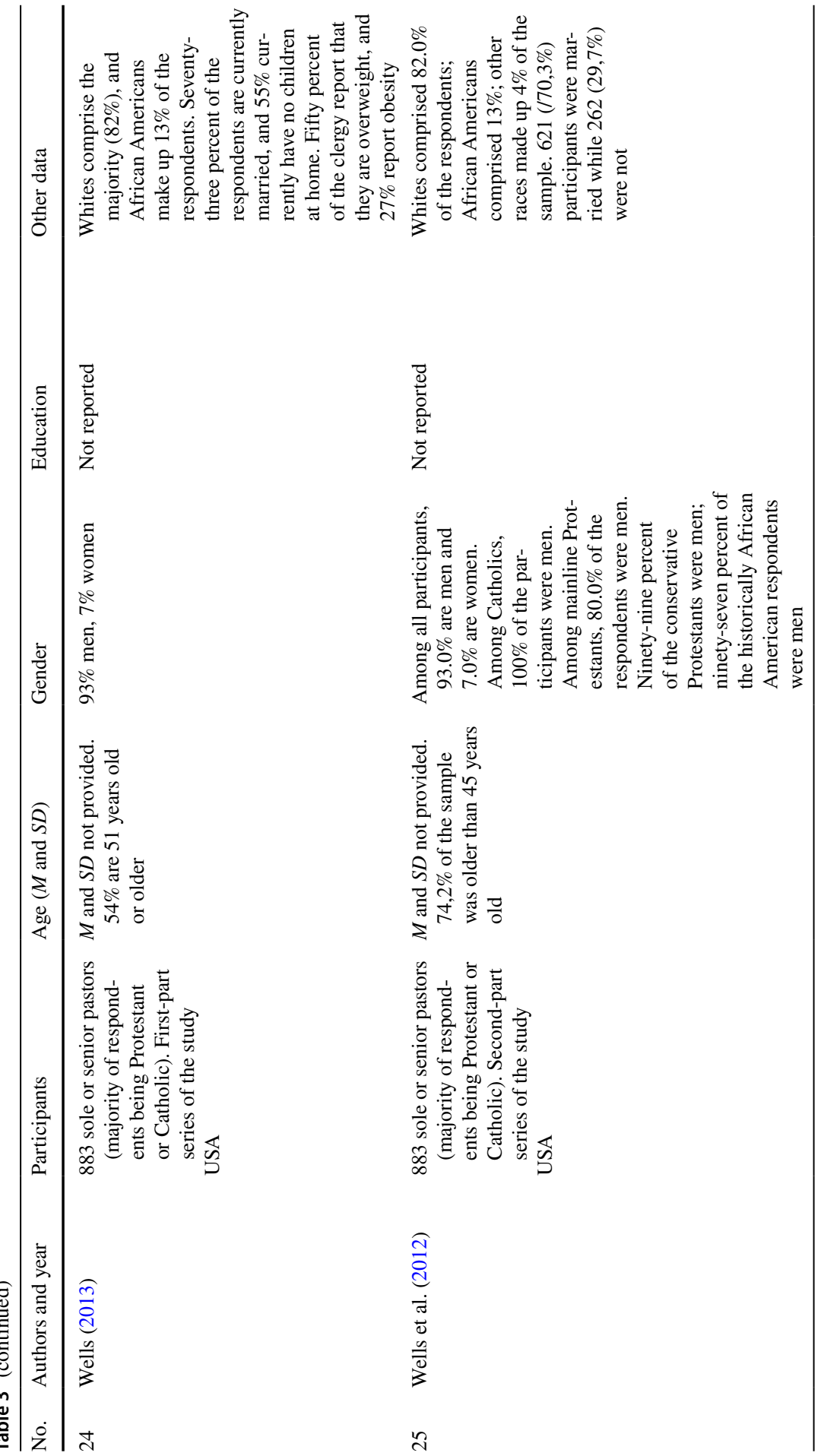




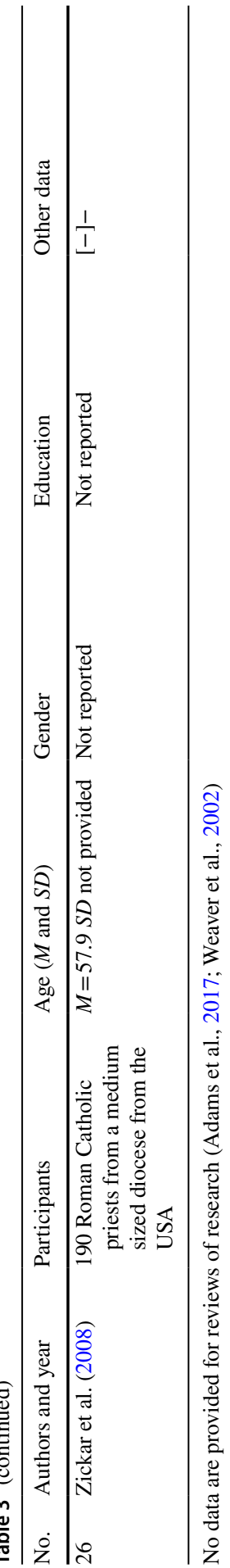

Springer 
$(r=0.33)$ and negatively with emotional exhaustion $(r=-0.34)$ and depersonalization $(r=-0.32)$. Similar results were found for agreeableness and conscientiousness, with results revealing negative correlations between agreeableness and emotional exhaustion $(r=-0.51)$ and between agreeableness and depersonalization $(r=-0.56)$ and positive correlations between conscientiousness and personal accomplishment $(r=0.35)$ and between conscientiousness and engagement $(r=0.44)$. No statistically significant correlations were observed between openness to experience, and the other variables studied.

Another key aspect to take into consideration is the way in which priests manage their emotions. In a study exploring how positive and negative emotions affect stress, Francis et al. (2004) found that the pressure of working with people all day results in around $25 \%$ of priests feeling exhausted, fatigued when they get up in the morning, weighed down by their responsibilities (emotionally drained) and blamed by parishioners for their problems, all of which renders them less patient, less able to listen and less concerned about what happens to their flock (depersonalization). Nevertheless, this negative emotionality is balanced by feelings of personal satisfaction at working with people $(90 \%)$ and by the conviction that what they do has a real positive impact on people's lives (70\%). It is also true, however, that only one-third of priests consider themselves to be truly effective in their job $(32 \%)$ and describe themselves as being very energetic (31\%).

With the same sample of 155 Italian Catholic priests described earlier in this paper, the same authors found that negative emotionality was mainly manifested in a cynical and biting sense of humor (20\%), a feeling of discouragement due to lack of support (23\%) and daily feelings of fatigue and irritation (28\%). Nevertheless, it was positive emotionality that was dominant in participating priests, manifested as a feeling of having made many worthwhile accomplishments in their current ministry (77\%), the conviction that their ministry gave real meaning and purpose to their lives $(83 \%)$ and the fact that they felt very happy with their decision to join the priesthood (90\%) (Francis et al., 2017). Similar results were reported by a study conducted by Francis and Crea (2018) 1 year later.

It is also important to take narcissistic styles within the clergy into account. The "messiah complex and mentality" means that both the priest himself and those who surround him have extremely high expectations of his performance. A priest who tries to serve a community to the very best of his ability and who sees it as his duty to be available $24 \mathrm{~h}$ a day, 7 days a week, will feel guilty about setting limits or turning down a request. A priest with narcissistic tendencies, which prompt him to constantly prove his staunch commitment and dedication, will struggle with high levels of stress and negative emotions (Isacco et al., 2014). Priests often feel the weight of their role and the pressure to always convey an appropriate image. In general, people join the priesthood with high ideals, enormous optimism and a strong commitment to helping people. However, as difficulties accumulate, priests may become susceptible to feelings of disillusionment and despair (Raj \& Dean, 2005).

Another factor linked to coping styles is expectation of self-efficacy, which is a protective factor against perceived stress (Frick et al., 2015). Büssing et al. (2013) found a statistically significant negative correlation between perceptions of selfefficacy and spiritual dryness associated with burnout syndrome among clergy 
$(r=-0.305 ; p<0.01)$. Priests with good self-efficacy expectations feel confident that they can successfully cope with unexpected events and find different solutions to problems. They also feel that if someone opposes them, they can find the means and ways to get what they want.

This need for differentiation has prompted some authors to suggest that authenticity (beyond the priestly role) and being constantly reminded of one's individuality may be protective factors (Isacco et al., 2014).

Moreover, according to Zickar et al. (2008), role ambiguity, role conflict and role overload correlate negatively with job satisfaction and organizational commitment (to the diocese), whereas role ambiguity correlates negatively with (mainly) job satisfaction $(r=-0.41 ; p<0.001)$ and organizational commitment $(r=-0.23$; $p<0.001)$.

\section{Living Conditions}

Another interesting category found in our research is related to the priest's living conditions. Specifically, one basic aspect of priests' living conditions is their place of residence. In many cases, since their living quarters adjoin their place of work, priests are available round the clock, being obliged to accede to all demands and attend to all requests, never being able to disconnect from their job (Isacco et al., 2014). Indeed, the limits between clergy's public and private life often become blurred (Frick et al., 2015). Furthermore, according to Raj and Dean (2005), the possibility of having a positive physical environment has a significant impact on personal accomplishment $(r=0.29, p<0.05)$ and depersonalization $(r=-0.22$, $p<0.05)$.

Another aspect is loneliness, which particularly affects diocesan priests who often live and work alone. Loneliness has frequently been associated with major symptoms of depression and burnout (Greene et al., 2017; Raj \& Dean, 2005).

In relation to how having hobbies and engaging in community life help minimize the negative impact of burnout among priests, findings indicate that while they may both be protective factors, the results fail to reach statistical significance (Francis et al., 2017).

Over recent years, studies have shown how having a pet can benefit people's occupational health. In a sample of 1,468 Catholic priests from England and Wales, it was found that $11 \%$ of clergy had a dog and $6 \%$ had a cat. Although previous research has found important social, psychological and medical benefits to owning a pet, no statistically significant association has been reported between having a cat and the three dimensions of burnout (emotional exhaustion, depersonalization and personal accomplishment). Moreover, among dog owners, scores for emotional exhaustion and depersonalization increased slightly, while scores for personal accomplishment were unaffected. One conclusion drawn by authors studying the clergy is that the results obtained with other populations can rarely be extrapolated to the situation experienced by priests. Thus, while owning a pet seems to facilitate social relations among people who feel isolated, in the case of priests, these interactions already exist, and are indeed plentiful, which is perhaps why the benefits of 
pets have not been observed among this group. Moreover, the fact of having to cope with illness, death and suffering on a daily basis prompts clergy to develop resources for coping with their own vulnerability. Finally, given their generally very busy schedules, priests may view pets more as just another responsibility (particularly in the case of dog owners) than as a source of "companionship" (Francis et al., 2007).

\section{Sociocultural Context}

We have found significant influence of sociocultural context in the reviewed papers. Another source of stress for members of the clergy is the negative image of the priesthood portrayed in the media, along with people's negative reactions and attitudes of suspicion and mistrust toward clerics. Priests feel shame and sadness over the harm caused to victims by fellow members of the Church (Isacco et al., 2014).

Moreover, priests represent sacred values, such as celibacy, which are consistent with centuries of church tradition. However, due to today's secularized society, fewer and fewer people are called to the priesthood, which in turn generates overload and concern about the future (Rossetti \& Rhoades, 2013). According to Kane (2017), in the USA, the number of Catholic priests has dropped over the last 50 years (1965-2014) from 58.632 to 38,275. Five decades ago, $94 \%$ of priests were involved in active ministry, whereas today, this number is just $68 \%$. Nevertheless, the number of parishes has remained the same, meaning that congregations that were previously served by more than one member of the clergy today have only one priest who, moreover, often has to divide his time between various different parishes.

\section{Demands of the Job}

As current research show, and based on demands-resources model, we found the following results. As regards the demands to which priests are subject, the list provided by authors seems endless. Firstly, clergy often have the feeling that their job never ends. According to some studies, many of them work up to $63 \mathrm{~h}$ per week and feel pressured into engaging in multiple activities, leaving them little free time for themselves. Moreover, they often perform highly repetitive tasks and work for many years with the same people (Raj \& Dean, 2005; Rossetti \& Rhoades, 2013).

Secondly, priests cannot always measure their job in terms of efficacy since there is often a lack of tangible results. Moreover, it is frequently hard to determine right from wrong in the decisions they make, leaving them vulnerable to criticism (Adams et al., 2017; Rossetti \& Rhoades, 2013).

Some specific tasks are particularly stressful; for example, officiating at funerals, helping parishioners cope with grief (Adams et al., 2017), and social-charitable work (Rossetti \& Rhoades, 2013). Being counselors is also sometimes difficult and priests need sufficient psychological tools to ensure that they can give good help and advice (Kane, 2017; Weaver et al., 2002). In many cases, tasks such as serving various different parishes or administering sacraments can only be carried out by priests, who consequently feel overwhelmed (Isacco et al., 2014). 
Organizational, management and administrative tasks are often perceived as stressful, since they are very time-consuming and not particularly appreciated by parishioners (Raj \& Dean, 2005). Furthermore, in relation to tasks such as doing the parish accounts, for example, priests are rarely trained or qualified for this job yet spend an enormous amount of their time doing it (Isacco et al., 2014).

The priestly lifestyle involves juggling multiple roles and boundaries and managing conflicts in the parish. Interpersonal boundaries can often be ambiguous. Working with people is a vital part of the priestly vocation and can be simultaneously both satisfactory and stressful. Priests sometimes think that people "do not hear the word of God," constantly complain about parish activities and are an endless source of conflict. It is certainly true that each individual has different priorities and a different history, and all personalities are complex. At the same time, however, and although managing multiple leaderships within a community is a complex task, priests acknowledge that those who do participate in parish life have much of value to contribute (Isacco et al., 2014).

Finally, dealing with people's expectations regarding what it means to be a good priest is often another source of stress and tension (Beebe, 2007; Isacco et al., 2014; Raj \& Dean, 2005; Rossetti \& Rhoades, 2013).

\section{Organizational Variables}

Related to organizational variables, we found some interesting results as well. The priests participating in the studies reviewed often referred to a lack of social support by parishioners and collaborators (feelings of isolation and loneliness), as well as to the absence of "networking" with other colleagues, as factors which increased their occupational stress (Büssing et al., 2017). Indeed, Zickar et al. (2008) found significant associations $(p<0.001)$ between support from fellow priests and parish staff and commitment to the diocese and job satisfaction. Thus, support from parish staff correlated positively with commitment to the diocese $(r=0.20)$ and job satisfaction $(r=0.29)$. For its part, support from fellow priests also correlated positively with commitment to the diocese $(r=0.32)$ and job satisfaction $(r=0.18)$.

These results are consistent with those found by Raj and Dean (2005). According to their study, social support has a positive impact on priests' sense of personal accomplishment $(r=0.29, p<0.05)$.

One key organizational variable is the attitude of bishops toward the clergy under them. Bishops are often remote and unapproachable figures, exercising their authority in such a way as to ensure an intensely hierarchical organizational system. In the Catholic Church, bishops determine whether or not deacons can be ordained, and once they are, to which parish they will be assigned, where they will live and how long they will have to work before retiring, etc. (Kane, 2017; Raj \& Dean, 2005). Returning to the study by Zickar et al. (2008), support from the bishop correlated strongly with commitment to the diocese $(r=0.57 ; p<0.001)$.

As regards priests' assessment of bishops as leaders of their organization, Kane (2017) points out that, in some recent studies, 68\% of clergy report a low level of trust in their bishop and his skills as a leader of diocesan pastoral life. At the same 
time, $59 \%$ of participants claimed that they receive minimal (or no) support from their bishop in response to excessive or unrealistic demands from parishioners that go well beyond both their abilities and availability. Bishops are not able to demonstrate sufficient levels of respectful leadership; they do not take the needs of their collaborators into account; they have trouble fostering an organizational climate conducive to personal growth; and are incapable of reconsidering a decision in light of disagreement from priests. The author concludes that bishops seem to be overly concerned with defending their power, even when this gives rise to unfair situations.

\section{Vocational and Spiritual Variables}

Another group of stressors is linked to the priestly role and vows of obedience. Specifically, the vow of obedience generates most difficulties when it is understood as blind, submissive following of orders and when, for example, it involves accepting a transfer to a different parish, with the personal and relational uprooting that this implies (Isacco et al., 2014).

In a qualitative study carried out with 15 diocesan priests from the USA, participants claimed that their promise of obedience had a positive effect on their health since it increased positive feelings linked to a freely made commitment, provided stability and fostered a stronger relationship with the Church. However, as explained above, obedience sometimes generates negative emotions, especially when priests come into conflict with their bishop. Celibacy also generates positive feelings. Moreover, by not being committed to one single person, priests can enjoy a varied and enriching set of relationships and are free to focus more on their vocation.

Büssing et al. (2013) explored spiritual dryness among Catholic priests in relation to burnout syndrome. Statistically significant $(p=<0.01)$ negative correlations were observed between spiritual dryness and "positive" variables such as daily spiritual experiences $(r=-0.660)$, active religious practices $(r=-0.453)$, optimism $(r=-0.414)$, life satisfaction $(r=-0.434)$ and engagement $(r=-0.438)$. Moreover, as expected, spiritual dryness was also found to be negatively associated (positive correlations) with the three subscales of burnout: emotional exhaustion $(r=0.464)$, depersonalization $(r=0.450)$ and low personal accomplishment $(r=0.441)$. Finally, it is often accompanied by certain pathologies, such as anxiety $(r=0.387)$ and depression $(r=0.544)$.

In a subsequent study, Büssing et al. (2017) confirmed that the elements that best explain spiritual dryness are: a lack of perception of the transcendent, low sense of coherence (understood as being "anchored" in a meaningful life, with clear goals), depressive symptoms and emotional exhaustion (typical of burnout).

It should not be forgotten that since priests tend to attribute a sacredness to their work, they often work longer and harder than people in other professions in order to maintain an adequate image of themselves and to avoid perceived failure (Adams et al., 2017).

Prayer was also revealed as an important protective factor. Indeed, problems with stress are sometimes linked to having given up the habit of praying. Prayer is associated with spiritual well-being (Isacco et al., 2014), and some authors have reported 
that the more time priests spend praying, the lower their level of emotional exhaustion. Nevertheless, nothing in the results suggests that praying has a positive impact on satisfaction in ministry (Francis et al., 2017), although those who spend more time engaged in spiritual reading and prayer were found to have a stronger sense of personal accomplishment and fewer symptoms of depression and burnout (Raj \& Dean, 2005).

Priests' relationship with God is also mentioned in some studies as a protective factor. Clergy who feel a connection with God are better able to deal with important issues, feel themselves to be an instrument in God's hands and view God as a traveling companion who supports them and gives meaning to their lives. Faith in God is experienced as a dynamic relationship which is intrinsically linked to their maturity as people. It also provides a connection which fosters positive emotions, decreases the impact of negative emotions and enables authenticity (Isacco et al., 2016).

Having a purpose in life correlates positively with satisfaction in ministry, and both elements correlate negatively with emotional exhaustion (Francis et al., 2017). Similar results were reported also by Raj and Dean (2005), who found significant correlations between vocational satisfaction and personal accomplishment $(r=0.29$, $p<0.05)$ and between vocational satisfaction and depersonalization $(r=-0.34$, $p<0.05)$. Personal accomplishment was also fostered by spiritual activities $(r=0.21$, $p<0.05)$.

\section{Comparative Studies}

Some studies present a sample of Christian ministers, including Catholic priests, highlighting those aspects that all have in common. For instance, in a sample of 1,288 clergy from different Christian denominations (Roman Catholic, Lutheran, Methodist and Baptist) in the USA, the authors found strong correlations between high scores for occupational stress and high blood pressure $(33.5 \%)$, high cholesterol (29\%), type 2 diabetes (10.4\%), heart disease (6.8\%), lung disease (2.3\%), arthritis $(15.4 \%)$, chronic stress disorder $(0.5 \%)$, hours worked per week (mean of $46.1 \mathrm{~h}$ ) and a sedentary lifestyle (mean of $6 \mathrm{~h}$ sitting a day) (Webb \& Chase, 2019). Other problems associated with work-related stress are: increased anxiety and depression among priests, isolation, sleep disorders, medical issues and feeling angry all the time (Greene et al., 2017; Webb \& Chase, 2019).

In the USA, 883 clergy from different Christian denominations responded to a questionnaire in which work-related stressors (conflicts, criticism about their ministry, role ambiguity, congregational challenges, etc.) were linked to boundary-related stressors (congregational demands, isolation, lack of personal and private time, little time for recreation). The results revealed a strong correlation $(r=0.63 ; p<0.0001)$ and a linear relationship between the two constructs (Beta $=0.81, \mathrm{SE}=0.03$; $p<0.0001$ ), with multiple regression analyses indicating that as work-related stress increases, boundary-related stress also becomes more intense (Wells et al., 2012).

As regards coping styles, Parker and Martin (2011) carried out a study with 200 Australian clergy from eight different Christian denominations (including the Catholic Church). The authors measured two basic job-related behaviors: approach (hope 
for success) and avoidance (fear of failure) and established four coping styles linked to participants' self-assessments: "success oriented" (high approach/low avoidance), "overstriving" (high approach/high avoidance), "self-protecting" (low approach/high avoidance) and "failure accepting" (low approach/high avoidance). Success-oriented clergy were found to be more engaged in their work, to use better cognitive and behavioral strategies (mastery orientation and self-efficacy, task management, planning and persistence, etc.) and to have lower burnout rates. Self-protecting clergy, on the other hand (who had higher levels of anxiety, lower levels of mastery orientation and poorer capacities), scored lower on both scales. The overstriving group scored highly for emotional exhaustion and the failure accepting group scored very low for engagement.

We have also seen that physical activity is an excellent preventive measure. Webb and Bopp (2016) designed a study with two groups of Christian clergies. One group followed a three-month physical activity regime specially designed for clergy called "Walking in faith," whereas the other "control" group followed no specific treatment. Clergy from both groups were selected on the basis of having a sedentary, insufficiently active lifestyle, being at an age characterized by intense pastoral activity and not having problems preventing them from engaging in physical exercise. The 12-week regime linked biblical texts with health recommendations, warning about the risks of a sedentary lifestyle, promoting the value of an active life, highlighting the importance of seeking social support when engaging in physical activity and explaining how physical activity can help people cope better with stress, etc. Biblical references were used to adapt the regime to participants' culture and beliefs (proven to be much more effective than the use of a standard program). As expected, the results revealed significant improvements in the sedentary behavior, physical activity and perceived self-efficacy of those in the experimental group, in comparison with the controls.

As to the differentiation of self and role, in a study in the USA with 343 clergy from different Christian denominations (Catholic priests represented $9 \%$ of all participants), Beebe (2007) found that when individuals feel able to distinguish between their personal identity (self) and their priestly role, as two clearly differentiated realities, they do not tend to over-identify with the congregations they serve (fusion) and do not experience a feeling of overload in relation to the demands placed on them. The ability to differentiate between self and role was found to predict low emotional exhaustion, low depersonalization and high personal accomplishment. For their part, role ambiguity and overload were associated with all three burnout symptom scales. High self-role differentiation was also linked both to better conflict management and to the competitive (particularly useful in emergency situations or when group values are at stake) and collaborative (searching for a mutually satisfying solution that takes everyone's interests into account) conflict resolution styles, whereas poor selfrole differentiation was associated with the avoiding and accommodating conflict resolution styles.

According to the effort-reward imbalance model, the priesthood could be included in the helping professions category. All helping professions involve high levels of intrinsic (perfectionism, job commitment, difficulty disconnecting from work obligations and a pressing need for success and approval) and extrinsic effort 
(heavy workload, scarce resources, high level of responsibility and role conflicts), coupled with low rewards (difficulties bringing about change in the world, earning a good salary, gaining other people's approval, developing one's professional career, etc.). Comparing the priesthood with other professions may help gauge the degree of work-related stress and burnout to which clergy are subject (Adams et al., 2017).

In a review of the literature (84 studies), Adams et al., 2017 found similar levels of emotional exhaustion among clergy from different Christian denominations as among social workers, counselors and emergency personnel, and lower levels in comparison with teachers and police officers. However, clergy were found to have higher levels of depersonalization than social workers and counselors, similar levels to teachers and lower levels than emergency personnel and police officers. Finally, priests had moderate burnout levels in terms of personal accomplishment, with their scores being higher than those of counselors, similar to those of social workers and teachers and lower than those of police officers and emergency personnel. Given the high stress levels to which clergy are subject, their moderate burnout levels suggest that they employ good coping strategies.

Using a similar approach, Rossetti and Rhoades (2013) administered a detailed questionnaire to a sample of 2,482 Catholic priests in the USA. Clergy were found to score lower for burnout than both the general population and those in other professions considered particularly vulnerable in this respect, such as medicine or the social services. Some of the elements found to protect priests from burnout were a satisfying spiritual life and a sense of inner peace, being happy as priests and satisfied with their job, regular physical exercise, having good friendships, having a good relationship with and feeling supported by colleagues and their bishop, having one day off a week and having a good self-image.

Other studies have focused on the differences between Catholic priests and clergy from other religions. For example, in comparison with Anglican clergy, Catholic priests from Wales and England were found to have higher levels of emotional exhaustion and depersonalization, although they also had a greater sense of personal accomplishment (Francis et al., 2004).

This group of studies also includes a literature review by Weaver et al. (2002), in which the authors found that Protestant clergy reported higher mean levels of occupational stress, stating that they felt isolated, unsupported, vulnerable and angry with parishioners, and that they had difficulty establishing boundaries. Catholic priests, brothers and sisters, on the other hand, reported fewer vocational pressures and claimed to feel more supported by their colleagues and institutions. Finally, the fact that Protestant clergy can marry was found to be positively linked to marital commitment, satisfaction and good communication. However, the level of public exposure to which the families of Protestant clergy are subject and the pressing demands of the job, which make striking a good work-life balance difficult, are important stressors which, on occasions, result in clergy leaving the ministry.

Comparisons can also be made within the Catholic priesthood between diocesan priests and priests belonging to religious orders (or religious priests). To this end, Raj and Dean (2005) conducted a study with Catholic priests in Southern India (50 diocesan priests and 51 religious priests), administering the Maslach Burnout Inventory and the Center for Epidemiological Studies-Depression questionnaire. 
Diocesan priests obtained worse results than their counterparts in religious orders in all three subscales of the Maslach Burnout Inventory (emotional exhaustion, depersonalization and personal accomplishment) and reported more depressive symptoms $\left(M_{\text {diocesan }}=1.91\right.$ vs. $\left.M_{\text {religious }}=1.60\right)$. Although no significant differences were observed between the two groups in either vocational satisfaction or spiritual activities, diocesan priests did score lower for social support $(M=18.96$ vs. $M=21.72)$ and relevance of the physical environment $(M=10.67$ vs. $M=11.66)$. The authors also observed differences in proactive behaviors within the organization. Thus, while diocesan priests were not encouraged to specialize in a field that may awaken their interest and felt themselves to be intensely involved at a personal level with the problems of their parishioners, religious priests tended to spend most of their time engaged in "non-pastoral" activities such as social work or educating children and youths, and felt encouraged by their superiors to further their training in those areas of knowledge best suited to their individual profile and the challenges faced by the religious order to which they belonged.

Within the Catholic Church, comparisons can also be made between the different pastoral professions in terms of the stress to which each is subject. For instance, in a study conducted in Germany with 8.574 pastoral professionals, of which 4.157 were priests, it was found that men had a worse perception of work-related stress, lower expectations of self-efficacy and lower levels of life satisfaction. The high scores reported in general for men ( $75.1 \%$ of the total sample) were strongly influenced by the results corresponding to priests ( $48 \%$ of the total), who scored highest for depression, somatization, stress perception and spiritual dryness and lowest for selfefficacy expectations and life satisfaction (Frick et al., 2015).

\section{Stress, Burnout and Health}

The last category included in our scoping review is the relation between stress, burnout and health. In a study designed to analyze how work-related stress and burnout affect clergy's health, Ferguson et al. (2015) found a significant relationship between stress and obesity. Clergy who feel more pressured, criticized, isolated and "bi-vocational" (i.e., feel they have more than one job) tend to experience greater stress and are more likely to become obese. Priests who are stressed see themselves as having fewer coping resources and their response is "evolutionary": they eat more fat and carbohydrates to ensure their "physical survival." Moreover, stress discourages physical exercise and may even alter the metabolism.

Similar results were reported by Wells (2013), who linked work-related stress and stress associated with a lack of interpersonal boundaries using participants' Body Mass Index. The results revealed a positive correlation between work-related stress and obesity $(r=0.18 ; p=0.0001)$ and a slightly stronger one between boundaryrelated stress and obesity $(r=0.21 ; p=0.0001)$.

In a study with 881 priests from Latin America, the authors found that $39.62 \%$ of participants had no symptoms of burnout, $60.38 \%$ had moderate levels of this disorder in some or all of its three dimensions, and $25.39 \%$ presented the syndrome in its fullest extent, with emotional exhaustion being the factor that best explained 
the problem (26.22\% of participants). A statistically significant correlation was observed between emotional exhaustion and smoking $(r=0.365 ; p=0.007)$, and depersonalization correlated with both alcohol use $(r=0.378 ; p=0.001)$ and smoking $(r=0.333 ; p=<0.001)$. However, in this study at least, personal accomplishment did not seem to affect the manifestation of burnout among clergy (López et al., 2014).

As protective factors, those who have one day off a week, take holidays, have the opportunity to take a sabbatical and have support groups (fellow clergy, friends, etc.) are less likely to suffer from stress. Having days off and rest periods enables clergy to withdraw from their public role, engage in physical exercise, cook healthy meals without being in a rush and spend time with their relatives. Physical exercise is one of the best predictors of occupational health. Also, support groups with peers are particularly healthy, since they give clergy the chance to share concerns and needs with people who have similar experiences in a safe, confidential environment, thus helping to mitigate the common feeling of social isolation (Ferguson et al., 2015; Webb \& Chase, 2019).

In the "Results" section, four tables are presented to organize the results of our revision. First table summarizes the steps of a scoping review process (see Table 1). Table 2 shows the main findings of the studies included in this review. On the other hand, Table 3 summarizes the most important sociodemographic data which comprises the samples of the studies reviewed. Finally, Table 4 presents the results regarding risk and protective factors.

\section{Conclusions}

As Arksey and O'Malley (2005) suggested, we followed the recommended steps to perform a scoping review of occupational stress factors over Catholic priest. We found some interesting results that may help readers to approach this complex topic. We can conclude that our objectives have been accomplished. We conducted a review of the most important factors found in the literature related to work-related Catholic priests' stress. Besides, we have offered to the readers a wide categorized optic of the influence of diverse variables over work-related Catholic priests' stress. Consequently, we can affirm that we have accomplished objectives 1 and 2 purposed in the current research. Having said this, we can conclude that catholic diocesan clergy, who live alone, have higher levels of anxiety and depression than those belonging to religious orders, who live within a community (Knox et al., 2002). According to Seghedoni (2012), rather than talking about loneliness or solitude, we should really be talking about "solitudes," in plural, since affective solitude (partly foreseen by clergy) is accompanied by pastoral solitude and institutional solitude also, which are often more harmful. According to this author, encounters between priests are often characterized by haste, pressure to make headway in a joint project and "gossip."

As seen earlier in this chapter, support from fellow priests is a powerful protective factor against stress (Zickar et al., 2008). For Uriarte (2010), a sense of "fraternity" encourages a spirit of collaboration among clergy, which in turn helps them 
Table 4 Risk and protection factors for stress among Catholic priests

Risk factors for stress

Personal characteristics

Neuroticism

Perfectionism

External locus of control

Type A personality profile; Narcissism

Role orientation

Avoidance coping style

Over complacency

Life conditions

Mismanagement of loneliness

Absence of support network and friends

Loneliness

Sedentary lifestyle

Absence of rest periods

Ecclesial and social context

Religious indifference

Spillage of social relevance

Excessive demands and expectations of parishioners. Clergies should be always available

Organizational climate and job satisfaction

Ambiguity and role conflict

Authoritarian leadership style

Pyramid scheme of work

Lack of closeness and concern of diocesan authorities
Protection factors for stress

Extroversion, responsibility and friendliness

Engagement and self-efficacy

Positive emotions (optimism)

Active coping style

Personal identity and authenticity

Competitive and collaborative styles of conflict resolution

Possibility of finding rest periods: vacation, days off, daily rest

Physical exercise, healthy diet

Health check

Relational world: other priests, friends, parishioners

Spiritual life (personal prayer)

Seeing the current context as an opportunity for improvement and innovation

Learning to set adequate boundaries

Clear terms of what is expected of clergy, betterdefined tasks

Leadership based on influence: motivating work climate

Teamwork and networking

Better opportunities to develop their skills (entrepreneurship, job crafting)

Blind obedience

be more efficient and avoid the loneliness of a "long-distance runner." However, as this author claims, fraternity is, above all, a question of identity: "Priests need other priests in order to be priests." This is consistent with the principles of social identity, which argue that a large part of a person's identity is constructed on the intergroup plane (Haslam et al., 2011).

Although the loneliness experienced by Catholic diocesan priests correlates strongly with mental health issues such as depression and stress, we should not idealize the family life of clergy from other denominations (Guzman and Teh 2016; Kim et al. 2016; Wilson and Darling 2017).

Turning from loneliness to the impact of age on stress, it is important to note that younger and middle-aged priests report higher stress levels. Among younger 
clergymen, this may, as Parolari (2006) suggests, be the result of their "insertion" into the priestly role. Young priests tend to focus on responding to the most obvious and pressing expectations in their environment (as expressed by people, the institution, their bishop, etc.), often without realizing the price that this will exact. They strive to earn the minimum level of consideration and esteem that provides them with confirmation of their own identity.

The fact that middle-aged priests also report high levels of work-related stress is consistent with that suggested by some authors, who argue that it is during this time in their lives that clergy are most productive and "generative." It should also be remembered that many priests continue to work actively until the age of 75 or 80 , and the results suggest that older clergy, who have fewer demands placed on them by an intense work schedule, are able to organize their working day in a more satisfactory manner (Garrido, 1997; Uriarte, 2011).

Priestly role also seems to play a key role in experiences of stress, with those who become absorbed in their clerical duties being more vulnerable to emotional exhaustion and depersonalization (Beebe, 2007; Zickar et al., 2008). According to Guarinelli (2014), we belong to a culture in which insistence on the search for one's psychological identity can be very strong. Yet at the same time, priests' psychosocial role no longer has the same force of identity as it did just a few decades ago. Perhaps this is why there is so much insistence on maintaining or recovering certain symbols, as a means of compensating for this weakening of the priestly identity.

Indeed, role ambiguity is an important explanatory factor for job dissatisfaction among clergy. Questions about role ambiguity referred to the clarity of the institution's aims, the balanced distribution of working times, a clear explanation of what clergy were expected to do, a clear definition of responsibilities and specific knowledge of what was expected of them. When role ambiguity is low, job satisfaction is adequate even if role conflict is high (Faucett et al., 2013).

In this sense, Rulla () points out that the vocational role should be understood as a resource at the service of "internal vocational consistency," rather than as and in itself. Thus, the actions deployed within the role should serve to strengthen the internal system of attitudes and vocational values; in other words, behaviors associated with the role should be internalized. In this way, the role is oriented toward values, since it enables ideal modes of behavior; the role is chosen in accordance with the system of values, but said system transcends the role itself.

As seen earlier, the figure of the bishop is perceived as distant and incapable of engaging in effective leadership. In this sense, Kane (2014) observed that although bishops "in general" were negatively assessed in terms of their leadership skills, when speaking of their particular bishop, participants gave a more detailed opinion and rated them slightly higher. Nevertheless, the research to which the author refers reveals a consistent relationship between poor leadership by bishops and high levels of discouragement, distress and depression among priests, whereas, as seen in the introductory chapter (Haslam et al., 2011; Moriano et al., 2014; Serrano-Orellana \& Portalanza, 2015), close and respectful leadership based on the key elements of social identity theory fosters (principally) engagement and other proactive and organizational citizenship behaviors (Orgambídez-Ramos et al., 2015). 
Within the field of proactive behaviors, one area which merits further research is the concept of "job crafting" applied to the lives of priests. The concept of "job crafting" is an original approach to the changes that an employee may make to his or her job, without redesigning the entire position. A better understanding of this phenomenon can be gained by analyzing its structure in four factors, in accordance with the Spanish version of the Job Crafting Scale (Bakker et al., 2018). Job crafting involves: (1) increasing structural job resources: development of capacities, professional development, ongoing learning of aspects related to the job, the employee decides how best to do things, etc. (2) Decreasing hindering job demands: the employee strives to ensure that their job is mentally and emotionally less intense. (3) Increasing social job resources: by asking supervisors and colleagues for advice and feedback. And (4) increasing challenging job demands: employees become involved in new projects they find interesting, are not afraid of learning and trying out new things, make use of the times when the workload is lighter to think about new projects and take on challenging tasks, etc.

Job crafting is a model which links the physical, social and organizational demands made of an employee in their job (and which normally take a physical and psychological toll) with the resources available to them. Someone who crafts their job minimizes the impact of these demands and uses all the skills they have attained, thereby ensuring high job satisfaction and effective management of occupational stress. To enable this, in addition to a proactive personality, employees also need (as seen above) an organizational climate which offers opportunities for this type of behavior (Wingerden \& Niks, 2017).

A priest who has the freedom, creativity, ability and initiative to design his own job will feel more satisfied, will identify more with his organization/Church and will be less vulnerable to work-related stress and burnout syndrome.

One last variable that is worth highlighting here is related to rest periods and selfcare. As seen earlier, the absence of boundaries in priests' lives, over-orientation toward the priestly role and the feeling of having too much demanded from them results in clergy finding it difficult to set time aside for themselves.

Research into a strategy known as "recovery" (Alcover, 2016; Demerouti et al., 2013) is of particular interest here. This strategy is linked to rest during holidays, weekends and days off, but in the case of Catholic clergy, it should be taken into account that being a priest is different from working in a secular profession and days off fall on different dates. Moreover, emphasis has recently been placed on the importance of daily recovery (during and after each working day). The aim of recovery is twofold: firstly, it seeks to minimize the effects of tension and stress, and secondly, from a more positive perspective, it aims to improve well-being.

Alcover (2016) calls attention to a fundamental aspect here: recovery occurs both outside the workspace (external recovery) and inside it, through either short pauses throughout the working day or regular changes of activity (internal recovery). The author distinguishes between semi-leisure activities (housework and personal care tasks), passive recreation (e.g., watching television) and active recreation (physical and social activities).

As the reviewed articles explain, while spiritual dryness and the absence of prayer are risk factors for experiencing occupational stress, spiritual well-being positively correlates with people's physical and emotional health. Research indicates that 
religious experiences protect from stress and positively influence the immune system, cardiovascular health, mental health, and healthy habits, etc. (Chirico, 2016).

Furthermore, for priests, a strong sense of vocation implies experiencing pastoral activity as a source of well-being. Priests face numerous demands every day and their working days can be long. However, having a consistent vocation makes them feel motivated to carry out their work. The task gives meaning to their lives because it is a response to the transcendent dimension: "answering God's call," "identifying with the Good shepherd." Viewing and experiencing pastoral activity as a generous gift rather than an exhausting chore is an important protective factor against occupational stress (John Paul II, 1979).

In this sense, Christian prayer (like other meditation techniques, such as mindfulness) elicits a "relaxation response" incompatible with occupational stress. Chirico et al. (2020) carried out an experiment with 50 teachers from a catholic school. The experimental group received two short weekly prayer training sessions for two months, significantly reducing their burnout levels and improving their job satisfaction compared to the control group.

Other previous research insists on the benefits of meditative prayer and religious practice, which are especially effective in consecrated participants. Consecrated women report a greater frequency of personal prayer, church attendance and subjective religiosity, which correlates positively with greater job satisfaction, fewer absences due to illness, less psychopathology and greater commitment to work, etc. (Chirico et al., 2017c).

As stated in the "Method" section, due to the scarcity of references identified in this field and the variability of the methods used, this study has the important limitation of serving only as an exploratory approach to the subject under analysis. However, its modest nature is also its main virtue, in that it reveals all the possibilities which exist for future study and research.

Another limitation is that the reviewed research did not provide exactly the same data. Due to this, it would be interesting to conduct an original research, controlling the possible odd variables. Besides, data are collected from different locations, which may impact in the results. Despite these limitations, our scoping review tries to provide the most rigorous amount of data. This is one of the limitations of the scoping reviews; on the contrary, this may help us to explore the subject matter, and future research should benefit of this analysis for designing new approaches.

It seems clear that, in light of everything outlined above, more research is required into diocesan clergy and their experiences of work-related stress, bearing in mind a series of moderator variables such as relationship with their bishop and fellow priests, sociodemographic variables, identification with the organization and proactive behavior.

It would also be interesting to find evidence in support of the idea proposed by López (2012), who claimed that, among Catholic clergy, burnout and boreout syndromes tend to occur simultaneously as manifestations of work-related stress.

As we have seen, from a holistic perspective of health, finding times and spaces for prayer will lead to better overall health. Catholic dioceses, schools and hospitals, etc., can implement "schools of prayer and spirituality" for their consecrated and lay 
members. The efficacy of these programs could even be subsequently investigated with a view to improving them (Chirico \& Magnavita, 2019).

Finally, in future research, it will be important to relate the impact of Covid-19 to occupational stress in priests. On the one hand, in such situations of crisis, people turn to spiritual comfort to help them deal with death and uncertainty about the future; yet on the other, priests (especially chaplains in hospitals, funeral homes and cemeteries, many of whom are elderly) face the burden of offering spiritual care, comfort in coping with grief and hope in the face of financial difficulties. Moreover, priests put their lives at risk by administering sacraments and spiritual care, both of which involve physical contact, and often do not feel respected by other health professionals or feel unprepared to offer their services online (Bramstedt, 2020). However, it should be remembered that sacraments (e.g., confession) cannot be administered online.

Funding Open Access funding provided thanks to the CRUE-CSIC agreement with Springer Nature.

\section{Declarations}

Conflict of interest The authors have no conflicts of interest to declare that are relevant to the content of this article.

Research involving Human Participants and/or Animals The present review does not include any primary study; hence, it does not involve human participants or animals.

Informed Consent Consequently, informed consent does not apply to our manuscript. [Please note that some references below require the titles to be italicized]

Open Access This article is licensed under a Creative Commons Attribution 4.0 International License, which permits use, sharing, adaptation, distribution and reproduction in any medium or format, as long as you give appropriate credit to the original author(s) and the source, provide a link to the Creative Commons licence, and indicate if changes were made. The images or other third party material in this article are included in the article's Creative Commons licence, unless indicated otherwise in a credit line to the material. If material is not included in the article's Creative Commons licence and your intended use is not permitted by statutory regulation or exceeds the permitted use, you will need to obtain permission directly from the copyright holder. To view a copy of this licence, visit http://creativecommons.org/licen ses/by/4.0/.

\section{References}

Adams, C. J., Hough, H., Proeschold-Bell, R., Yao, J., \& Kolkin, M. (2017). Clergy burnout: A comparison study with other helping professions. Pastoral Psychology, 66(2), 147-175. https://doi.org/10. 1007/s11089-016-0722-4

Alcover, C. M. (2016). Recuperación del trabajo, bienestar psicosocial y salud ocupacional. [Job recovery, Psychosocial Wellbeing and Occupational Health]. In C. M. Alcover, G. Topa, \& J. A. Moriano (Eds.), Psicología del trabajo, conceptos claves y temas emergentes [Occupational psychology, key concepts and emerging issues]. Sanz y Torres.

Antonovsky, A. (1987). Unraveling the mystery of health: How people manage stress and stay well. Jossey-Bass 
Arksey, H., \& O’Malley, L. (2005). Scoping studies: Towards a methodological framework. International Journal of Social Research Methodology, 8(1), 19-32. https://doi.org/10.1080/136455703200011 9616

Asante, E. A., \& Affum-Osei, E. (2019). Entrepreneurship as a career choice: The impact of locus of control on aspiring entrepreneurs' opportunity recognition. Journal of Business Research, 98, 227235. https://doi.org/10.1016/j.jbusres.2019.02.006

Bakker, A. B., \& Demerouti, E. (2013). La teoría de las demandas y los recursos laborales [Job demandsresources Model]. Journal of Work and Organizational Psychology, 29, 107-115. https://doi.org/ $10.5093 / \operatorname{tr} 2013 \mathrm{a} 16$

Bakker, A. B., Ficapal-Cusí, P., Torrent-Sellens, J., Boada Grau, J., \& Hontangas-Beltrán, P. M. (2018). The Spanish version of the Job Crafting Scale. Psicothema, 30(1), 136-142. https://doi.org/10. 7334/psicothema2016.293

Beebe, R. S. (2004) Assessing self and role in clergy. Relationships between burnout, conflict management style, and turnover. Dissertation, State Universiyt of New York, Buffalo.

Beebe, R. S. (2007). Predicting burnout, conflict management style, and turnover among clergy. Journal of Career Assessment, 15(2), 257-275. https://doi.org/10.1177/1069072706298157

Bramstedt, K. A. (2020). COVID-19 as a cause of death for Catholic priests in Italy: An ethical and occupational health crisis. Health and Social Care Chaplaincy, 8(2), 180-190. https://doi.org/10.1558/ hscc. 41620

Büssing, A., Ostermann, T. \& Matthiessen, P.F. (2005). Role of religion and spirituality in medical patients: Confirmatory results with the SpREUK questionnaire. Health Qual Life Outcomes 3, 10. https://doi.org/10.1186/1477-7525-3-10

Büssing, A., Baumann, K., Jacobs, C., \& Frick, E. (2017). Spiritual dryness in catholic priests: Internal resources as possible buffers. Psychology of Religion and Spirituality, 9(1), 46-55. https:// doi.org/10.1037/re10000063

Büssing, A., Günther, A., Baumann, K., Frick, E., \& Jacobs, C. (2013). Spiritual dryness as a measure of a specific spiritual crisis in catholic priests: Associations with symptoms of burnout and distress. Evidence-Based Complementary and Alternative Medicine. Article ID 246797. https:// doi.org/10.1155/2013/246797

Cabrera, L. E. (2014). Síndrome de Boreout: Diseño, confiabilidad y validación preliminar de un instrumento para su medición [Boreout syndrome: design, reliability and preliminary validation of an instrument for measuring]. Revista De La Universidad Industrial De Santander Salud, 46(3), 259-265. https://doi.org/10.18273/revsal

Chirico, F. (2016). Spiritual well-being in the 21st century: It is time to review the current WHO's health definition. Journal of Health and Social Sciences., 1(1), 11-16. https://doi.org/10.19204/ 2016/sprt2

Chirico, F. (2017b). Is burnout a syndrome or an occupational disease? Instructions for occupational physicians. Epidemiologia e Prevenzione, 41(5-6), 294-298. https://doi.org/10.19191/EP17.5-6.P294. 089

Chirico, F. (2017a). Burnout and depression are not the same thing. The British Journal of Psychiatry, 190(1), e-letter. https://doi.org/10.1192/bjp.190.1.81a

Chirico, F. (2017c). Religious belief and mental health in lay and consecrated Italian teachers. Journal of Religion and Health, 56(3), 839-851. https://doi.org/10.1007/s10943-016-0242-7

Chirico, F., \& Magnavita, N. (2019). The spiritual dimension of health for more spirituality at workplace. Indian Journal of Occupational and Environmental Medicine, 23(2), 98-99. https://doi.org/10. 4103/ijoem.IJOEM_209_18

Cohen, S., Kamarck, T., \& Mermelstein, R. (1983). A Global Measure of Perceived Stress. Journal of Health and Social Behavior, 24(4), 385-396. https://doi.org/10.2307/2136404

Chirico, F., Sharma, M., Zaffina, S., \& Magnavita, N. (2020). Spirituality and prayer on teacher stress and burnout in an Italian cohort: A pilot, before-after controlled study. Frontiers in Psychology, 10, 2933. https://doi.org/10.3389/fpsyg.2019.02933

Congregation for the clergy. (2016). El don de la vocación presbiteral: Ratio fundamentalis institutionis sacerdotalis. [The gift of the priestly vocation: Ratio fundamentalis institutionis sacerdotalis]. San Pablo.

Costa, P. T., \& McCrae, R. R. (1992). Normal personality assessment in clinical practice: The NEO Personality Inventory. Psychological Assessment, 4(1), 5-13. https://doi.org/10.1037/1040-3590.4.1.5

Cozzens, D. B. (2003). La faz cambiante del sacerdocio [The changing fase of the priesthood]. Sal Terrae. 
Craig, C. L., Marshall, A. L., Sjostrom, M., Bauman, A. E., Booth, M. L., Ainsworth, B. E., Pratt, M., Ekelund, U., Yngve, A., Sallis, J. F., \& Oja, P. (2003). International Physical Activity Questionnaire: 12 country reliability and validity. Medicine \& Science in Sports \& Exercise, 35(8), 13811395. https://doi.org/10.1249/01.MSS.0000078924.61453.FB

Crea, G., \& Mastrofini, F. (2010). Preti sul lettino. Giunti.

Derogatis, L. R., \& Savitz, K. L. (2000). The SCL-90-R and Brief Symptom Inventory (BSI) in primary care. In M. E. Maruish (Ed.), Handbook of Psychological Assessment in Primary Care Settings (pp. 297-334). Lawrence Erlbaum Associates Publishers.

Derogatis, L. R. (2001). Brief Symptom Inventory-18 BSI-18. Administrationn, Scoring, and Procedures Manual. NCS Pearson.

Diener, E. D., Emmons, R. A., Larsen, R. J., \& Griffin, S. (1985). The satisfaction with life scale. Journal of Personality Assessment, 49(1), 71-75. https://doi.org/10.1207/s15327752jpa4901_13

De Miguel, J., Gallardo, I., Horcajo, J., Becerra, A., Aguilar, P., \& Briñol, P. (2009). El efecto del estrés sobre el procesamiento de mensajes persuasivos. [The impact of stress on processing persuasive messages]. Revista De Psicología Social, 24(3), 399-409. https://doi.org/10.1174/0213474097 89050597

Demerouti, E., Bakker, A. B., \& Sanz-Vergel, A. (2013). Recovery and work-life interface. In D. A. Major \& R. J. Burke (Eds.), Handbook of work-life integration among professionals (pp. 225-244). Edward Elgar Publishing. https://doi.org/10.4337/9781781009291.00022

Durán, M. M. (2010). Bienestar Psicológico: El estrés y la calidad de vida en el contexto laboral. [Stress and quality of life in the work context]. Revista Nacional De Administración, 1(1), 71-84. https:// doi.org/10.22458/rna.v1i1.285

Endler, N.S., Parker J. D. (1990). Multidimensional assessment of coping: A critical evaluation.. Journal of Personality and Social Psychology 58(5) 844-854. https://doi.org/10.1037/0022-3514.58.5.844

Ewing, J. A. (1984). Detecting alcoholism: the CAGE questionnaire. JAMA, 252(14), 1905-1907. https:// doi.org/10.1001/jama.1984.03350140051025

Eysenck, H. J. \& Eysenck, S. B. G. (1975). Manual of the Eysenck Personality Questionnaire. Hodder \& Stoughton.

Faucett, J. M., Corwyn, R. F., \& Poling, T. H. (2013). Clergy role stress: Interactive effects of role ambiguity and role conflict on intrinsic job satisfaction. Pastoral Psychology, 62, 291-304. https://doi. org/10.1007/s11089-012-0490-8

Ferguson, T. W., Andercheck, B., Tom, J. C., Martinez, B. C., \& Stroope, S. (2015). Occupational conditions, self-care, and obesity among clergy in the United States. Social Science Research, 49, 249263. https://doi.org/10.1016/j.ssresearch.2014.08.014

Francis, L. J., \& Crea, G. (2015). Work-related psychological health and psychological type: A study among catholic priests in Italy. Mental Health, Religion \& Culture, 18(7), 593-604. https://doi.org/ 10.1080/13674676.2014.963996

Francis, L. J., \& Crea, G. (2018). Happiness matters: Exploring the linkages between personality, personal happiness, and work-related psychological health among priests and sisters in Italy. Pastoral Psychology, 67(1), 17-32. https://doi.org/10.1007/s11089-017-0791-z

Francis, L. J., Laycock, P., \& Crea, G. (2017). Assessing clergy work-related psychological health: Reliability and validity of the Francis Burnout Inventory. Mental Health, Religion \& Culture, 20(9), 911-921. https://doi.org/10.1080/13674676.2017.1373333

Francis, L. J. (2005). Faith and Psychology: Personality, religion and the individual. Darton, Longman \& Todd.

Francis, L. J., Louden, S., \& Rutledge, C. (2004). Burnout among Roman Catholic parochial clergy in England and Wales: Myth or reality? Review of Religious Research, 46, 5-19. https://doi.org/10. $2307 / 3512249$

Francis, L. J., Turton, D. W., \& Louden, S. H. (2007). Dogs, cats and catholic parochial clergy in England and Wales: Exploring the relationship between companion animals and work-related psychological health. Mental Health, Religion \& Culture, 10(1), 47-60. https://doi.org/10.1080/1367467060 1012329

Franke, G. H. (1997). Ersten Studien zur Güte des Brief Sympton Inventory (BSI). Zeitschrift für Medizinische Psychologie, 6, 159-166

Franke, G. H. (2000). Brief Symptom Inventory von L. R. Derogatis (Kurzform de SCL-90-R). Beltz Test Franke, G. H., Ankerhold, A., Haase, M., Jäger, S., Tögel, C., Ulrich, C., \& Frommer, J. (2011) Der Einsatz des Brief Symptom Inventory 18 (BSI-18) bei Psychotherapiepatienten. PPmP 
- Psychotherapie Psychosomatik Medizinische Psychologie 61(02) 82-86. https://doi.org/10.1055/ S-0030-1270518

Frenk, S. M., Mustillo, S. A., Hooten, E. G., \& Meador, K. G. (2013). The Clergy Occupational Distress Index (CODI): Background and findings from two samples of clergy. Journal of Religion and Health, 52(2), 397-407. https://doi.org/10.1007/s10943-011-9486-4

Frick, E., Bussing, A., Baumann, K., Weig, W., \& Jacobs, C. (2015). Do self-efficacy expectation and spirituality provide a buffer against stress-associated impairment of health? A comprehensive analysis of the German Pastoral Ministry Study. Journal of Religion and Health, 55(2), 448-468. https://doi.org/10.1007/s10943-015-0040-7

Fydrich, M., Geyer,M., Hessel, A., Sommer, G., Brähler, E. (1999). Fragebogen zur Sozialen Unterstützung (F-SozU): Normierung an einer repräsentativen Stichprobe. Diagnostica 45(4) 212-216. https://doi.org/10.1026//0012-1924.45.4.212

Gall, T. L. (2000). Integrating religious resources within a general model of stress and coping: Long-term adjustment to breast cancer. Journal of Religion and Health, 39(2), 167-182. https://doi.org/10. 1023/A:1004670717144

García, R. M., Ortega, S., Gonzales, A., López, E., \& Ludwing, L. (2015). El patrón de conducta tipo A y el trabajo. Un estudio sobre satisfacción laboral. [Management style A and job: a study about job satisfaction]. ReiDoCrea, 4, 100-105. https://doi.org/10.30827/Digibug.37010

Garrido, J. (1997). Releer la propia historia. [Rereading one's own history]. Frontera.

Gerlitz, J. Y., \& Schupp, J. (2005). Zur Erhebung der Big-Five-basierten Persönlichkeitsmerkmale im SOEP. Deutsches Institut für Wirtschaftsforschung.

Gilbert, P., McEwan, K., Matos, M., \& Rivis, A. (2011). Fears of compassion: Development of three selfreport measures. Psychology and Psychotherapy: Theory, Research and Practice, 84, 239-255. https://doi.org/10.1348/147608310X526511

Gil-Lacruz, M., \& e Izquierdo, A. (2004). Intervención en el patrón de conducta tipo A: Un modelo interdisciplinary. [Intervención in the A conduct pattern: An interdisciplinar model]. Persona, 7, 71-85. https://doi.org/10.26439/persona2004.n007.889

Glaesmer, H., Hoyer, J., Klotsche, J., \& Herzberg, P. (2008). Die deutsche Version des Life-OrientationTests (LOT-R) zum dispositionellen Optimismus und Pessimismus. Zeitschrift für Gesundheitspsychologie 16(1) 26-31. https://doi.org/10.1026/0943-8149.16.1.26

Gnani, E. (2013). I conflitti di ruolo nel ministero. Tredimensioni, 10, 89-98.

Gómez, C. (2009). Salud psicológica y realización humana. Estudio teórico-empírico. [Psychological health and human fulfilment. A theoretical-empirical study]. Instituto Teológico Compostelano.

Greene, D. C., Brennan, C., \& Britton, P. J. (2017). Exploration of psychological distress in gay, bisexual, and heterosexual roman catholic priests. Psychology of Religion and Spirituality, 9(4), 401-411. https://doi.org/10.1037/rel0000047

Guarinelli, S. (2014). El sacerdote inmaduro. [The immature priest]. Sígueme.

Guzman, N. E. Q., \& Teh, L. A. (2016). Understanding the stresses and coping resources of Filipino clergy families: A multiple-case study. Pastoral Psychology, 65(4), 459-480. https://doi.org/10. 1007/s11089-016-0698-0

Haslam, S. A., Reicher, S. D., \& Platow, M. J. (2011). El liderazgo como gestión de la identidad social [Leadership as social identity management]. In F. Molero \& J. F. Morales (Eds.), Liderazgo: hecho y ficción. Visiones actuales (pp. 77-116). Alianza.

Hills, P., \& Argyle, M. (2002). The Oxford Happiness Questionnaire: a compact scale for the measurement of psychological well-being. Personality and Individual Differences, 33(7), 1073-1082. https://doi.org/10.1016/S0191-8869(01)00213-6

Hinz, A., Schumacher, J., Albani, C., Schmid, G., \& Brähler, E. (2006) Bevölkerungsrepräsentative Normierung der Skala zur Allgemeinen Selbstwirksamkeitserwartung. Diagnostica 52(1) 26-32. https://doi.org/10.1026/0012-1924.52.1.26

Isacco, A., Sahker, E., Hamilton, D., Mannarino, M. B., Sim, W., \& St Jean, M. (2014). A qualitative study of mental health help-seeking among catholic priests. Mental Health, Religion and Culture, 17(7), 741-757. https://doi.org/10.1080/13674676.2014.910759

Isacco, A., Sahker, E., Krinock, E., Sim, W., \& Hamilton, D. (2016). How religious beliefs and practices influence the psychological health of catholic priests. American Journal of Men's Health, 10(4), 325-337. https://doi.org/10.1177/1557988314567325

John Paul II. (1979). Letter of his holiness John Paul II to all the priests on the occasion of Holy Thursday 1979. http://www.vatican.va/content/john-paul-ii/en/letters/1979/documents/hf_jp-ii_let_ 19790409_sacerdoti-giovedi-santo.html. 
John Paul, I. I. (1992). Pastores Dabo Vobis: sobre la formación de los sacerdotes en la situación actual [Pastores Dabo Vobis: on the formation of priests in the circumstances of the present day]. Librería Editrice Vaticana.

Joseph, E. N., Luyten, P., Corveleyn, J., \& De Witte, H. (2011). The relationship between personality, burnout, and engagement among the Indian clergy. International Journal for the Psychology of Religion, 21(4), 276-288. https://doi.org/10.1080/10508619.2011.607412

Kane, M. N. (2014). U.S. Catholic priests' evaluation of bishops and qualities of respectful leadership. Mental Health, Religion \& Culture, 17(3), 271-283. https://doi.org/10.1080/13674676.2013. 796917

Kane, M. N. (2017). Stress and relaxation among aging catholic priests. Journal of Spirituality in Mental Health, 19(1), 1-19. https://doi.org/10.1080/19349637.2016.1157566

Kessler, R. C., Barker, P. R., Colpe, L. J., Epstein, J. F., Gfroerer, J. C., Hiripi, E., Howes, M. J., Normand, S. L., Manderscheid, R. W., Walters, E. E., \& Zaslavsky, A. M. (2003) Screening for Serious Mental Illness in the General Population. Archives of General Psychiatry 60(2) 184-189. https:// doi.org/10.1001/archpsyc.60.2.184

Kilmann, R. H., \& Thomas, K. W. (1977). Developing a forced-choice measure of conflict-handling behavior: The "MODE" instrument. Educational and Psychological Measurement, 37(2), 309-325. https://doi.org/10.1177/001316447703700204

Kim, S., Corbett, T. M., Strenger, N., \& Lee, C. (2016). An Actor-Partner interdependence analysis of the ABC-X stress model among clergy couples. Psychology of Religion and Spirituality, 8(1), 65-76. https://doi.org/10.1037/rel0000031

Knox, S., Virginia, S., \& Lombardo, P. J. (2002). Depression and anxiety in Roman Catholic clergy. Pastoral Psychology, 50, 345-359. https://doi.org/10.1023/A:1014461603872

Leiter, M. P., \& Maslach, C. (2017). Burnout and engagement: Contributions to a new vision. Burnout Research, 5, 55-57. https://doi.org/10.1016/j.burn.2017.04.003

López, H. (2009). Incidencia del síndrome de burnout en sacerdotes católicos latinoamericanos y su relación con la inteligencia emocional. [Incidence of burnout syndrome in Latin American Catholic priests and its relationship with emotional intelligence]. Ph.D. Thesis, Universidad de Salamanca.

López, H. (2012). Sacerdocio y burnout. El desgaste en la vida sacerdotal. [Priesthood and burnout. Burnout in Priestley life]. San Pablo.

López, H., Pedrosa, I., Vicente, M. P., Suarez-Álvarez, J., Galindo, M. P., \& Garcia-Cueto, E. (2014). Multivariate analysis of burnout syndrome in Latin-American priests. Psicothema, 26(2), 227-234. https://doi.org/10.7334/psicothema2013.178

Lowney, C. (2018). Todos somos líderes. [We are all leaders]. Sal Terrae.

Luceño, L., Martín, J., Rubio, S., \& Díaz, E. (2004). Factores psicosociales en el entorno laboral, estrés y enfermedad. [Psychosocial factors in the work environment, stress and illness]. EduPsykhé, 3(1), 95-108.

Martin, A. J. (2007). The motivation and Engagement Scale. Lifelong Achievement Group.

Man-Ging, C. I., Frick, E., \& Baumann, K. (2018). Coping mechanisms for psychosomatic symptoms among aging roman catholic German priests. Journal of Religion and Health, 57(5), 1793-1807. https://doi.org/10.1007/s10943-018-0582-6

Maslach, C. (2017). Finding solutions to the problem of burnout. Consulting Psychology Journal: Practice and Research, 69(2), 143-152. https://doi.org/10.1037/cpb0000090

Maslach, C., Jackson, S. E., \& Leiter, M. P. (1996). Maslach Burnout Inventory Manual. Consulting Psychologists Press.

Maslach, C., Jackson, S. E. (1981) The measurement of experienced burnout. Journal of Organizational Behavior 2(2) 99-113. https://doi.org/10.1002/job.4030020205

Maslach, C. (1982). Burnout. The cost of caring. Prentice-Hall.

Moriano, J. A., Molero, F., \& Topa, G. (2014). The influence of transformational leadership and organizational identification on intrapreneurship. International Entrepreneurship and Management Journal, 10, 103-119. https://doi.org/10.1007/s11365-011-0196-x

Mowday, R. T., Steers, R. M., \& Porter, L. W. (1979). The measurement of organizational commitment. Journal of Vocational Behavior, 14(2), 224-247. https://doi.org/10.1016/0001-8791(79)90072-1

Orgambídez-Ramos, A., Pérez-Moreno, P. J., \& Borrego-Alés, Y. (2015). Estrés de rol y satisfacción laboral: Examinando el papel mediador del engagement en el trabajo. Revista De Psicología Del Trabajo y De Las Organizaciones, 31(2), 69-77. https://doi.org/10.1016/j.rpto.2015.04.001 
Osipow, S. H. (1998) Occupational Stress Inventory-Revised Edition (OSI-R): Professional Manual. Psychological Assessment Resources, Inc.

Pargament, K., Feuille, M., \& Burdzy, D. (2011). The Brief RCOPE: Current psychometric status of a short measure of religious coping. Religions, 2(1), 51-76. https://doi.org/10.3390/rel2010051

Parker, P. D., \& Martin, A. J. (2011). Clergy motivation and occupational well-being: Exploring a quadripolar model and its role in predicting burnout and engagement. Journal of Religion and Health, 50(3), 656-674. https://doi.org/10.1007/s10943-009-9303-5

Parolari, E. (2006). Reggere la conflittualità. Il Prete e L'istituzione. Tredimensioni, 3, 307-315.

Pawson, R., 2002. Evidence and policy and naming and shaming. Policy Studies, 23 (3/4), 211-230. https://doi.org/10.1080/0144287022000045993

Press Office of the Holy See (2019, June 6). Presentación del Anuario Pontificio 2019 y del "Annuarium Statisticum Ecclesiae 2017”. Retrieved from https://press.vatican.va/content/salastampa/es/bolle ttino/pubblico/2019/03/06/pres.html.

Raj, A., \& Dean, K. E. (2005). Burnout and depression among catholic priests in India. Pastoral Psychology, 54(2), 157-171. https://doi.org/10.1007/s11089-005-6200-z

Rizzo, J. R., House, R. J., \& Lirtzman, S. I. (1970). Role conflict and ambiguity in complex organizations. Administrative Science Quarterly, 15(2), 150-163. https://doi.org/10.2307/2391486

Robbins, M., \& Francis, L. J. (2000). Religion, personality, and well-being: The relationship between church attendance and purpose in life. Journal of Research on Christian Education, 9(2), 223-238. https://doi.org/10.1080/10656210009484908

Rossetti, S. J., \& Rhoades, C. J. (2013). Burnout in catholic clergy: A predictive model using psychological and spiritual variables. Psychology of Religion and Spirituality, 5(4), 335-341. https://doi.org/ 10.1037/a0033639

Rulla, L. M. (1986). Psicología profunda y vocación: I Las personas. [Depth psychology and vocation: I People]. Berlin: Atenas.

Rulla, L. M. (1990). Antropología de la vocación cristiana: 1 Bases interdisciplinares. [Anthropology of the Christian vocation: 1 Interdisciplinary basis]. Atenas.

Russell, D., Cutrona, C. E., Rose, J., \& Yurko, K. (1984). Social and emotional loneliness: an examination of Weiss's typology of loneliness. Journal of Personality and Social Psychology, 46(6), 13131321. https://doi.org/10.1037/0022-3514.46.6.1313

Rutledge, C). \& Francis, L. J. (2004). Burnout among male Anglican parochial clergy in England: Testing a modified form of the Maslach Burnout Inventory. Research in the Social Scientific Study of Religion, 15(1), 71-93.

Salanova, M., Bresó, E., \& Schaufeli, W. B. (2005). Hacia un modelo espiral de las creencias de eficacia en el estudio del Burnout y del Engagement. [Towards a spiral model of the efficacy beliefs in the study of burnout and engagement]. Ansiedad y Estrés, 11(2-3), 215-231.

Seghedoni, I. (2012). Questioni centrali da affrontare per il ministero oggi. Tredimensioni, 9, 280-289.

Serrano-Orellana, B. J., \& Portalanza, A. (2015). Influencia del liderazgo sobre el clima organizacional. Suma De Negocios, 5(11), 117-125. https://doi.org/10.1016/S2215-910X(14)70026-6

Schaufeli, W., Salanova, M., González-romá, V., \& Bakker, (2002). The Measurement of Engagement and Burnout: A Two Sample Confirmatory Factor Analytic Approach. Journal of Happiness Studies, 3, 71-92. https://doi.org/10.1023/A:1015630930326

Scheier, M. F., Carver, C. S., \& Bridges, M. W. (1994). Distinguishing optimism from neuroticism (and trait anxiety, self-mastery, and self-esteem): A reevaluation of the Life Orientation Test. Journal of Personality and Social Psychology, 67(6), 1063-1078.

Schwarzer, R., \& Jerusalem, M. (1995). Optimistic self-beliefs as a resource factor in coping with stress. In S. E. Hobfoll \& M. W. de Vries (eds.): Extreme Stress and Communities: Impact and Intervention. NATO ASI Series (Series D: Behavioural and Social Sciences), vol. 80. Springer.

Spanish Episcopal Conference. (2017). Comisión del Clero. [Clergy Commission]. Retrieved 2019, September 20, from https://conferenciaepiscopal.es/c-e-del-clero/.

Stanton, J. M., Sinar, E. F., Balzer, W. K., Julian, A. L., Thoresen, P., Aziz, S., ... \& Smith, P. C. (2002). Development of a compact measure of job satisfaction: The abridged Job Descriptive Index. Educational and psychological measurement, 62(1), 173-191. https://doi.org/10.1177/0013164402 06200112

Tajfel, H., \& Turner, J. (1979). An integrative theory of intergroup conflict. In W. G. Austin \& S. Worchel (Eds.), The social psychology of intergroup relations (pp. 33-47). Brooks/Cole.

Terry, J. D., \& Cunningham, C. J. (2020). The sacred and stressed: Testing a model of clergy health. Journal of Religion and Health, 59(3), 1541-1566. https://doi.org/10.1007/s10943-019-00920-9 
Uriarte, J. M. (2010). Una espiritualidad sacerdotal para nuestro tiempo. [A priestly spirituality for our times]. Sal Terrae.

Uriarte, J. M. (2011). Servir como pastores. Claves de la espiritualidad Sacerdotal. [Serving as Pastors. Keys to Priestly Spirituality]. Sal Terrae.

Urrútia, G. (2006). Formulando la pregunta de investigación. [Formulating the research question]. In J.L, R-Martín, A. Tobías \& T. Seoane, (Coord.), Revisiones Sistemáticas en las Ciencias de la Vida. El concepto de Salud a través de la síntesis de la Evidencia Científica (pp. 119-133). FISCAM - Fundación para la Investigación Sanitaria en Castilla-La Mancha.

Urrútia, G., \& Bonfill, X. (2010). Declaración PRISMA: una Propuesta para Mejorar la Publicación de Revisiones Sistemáticas y Metaanálisis. [PRISMA declaration: a proposal to improve the publication of systematic reviews and meta-analyses]. Medicina Clínica, 135(11), 507-511. https://doi. org/10.1016/j.medcli.2010.01.015

Underwood, L. G. (2011). The daily spiritual experience scale: Overview and results. Religions, 2(1), 29-50. https://doi.org/10.3390/rel2010029

Underwood, L. G., \& Teresi, J. A. (2002). The daily spiritual experience scale: Development, theoretical description, reliability, exploratory factor analysis, and preliminary construct validity using healthrelated data. Annals of Behavioral Medicine, 24(1), 22-33. https://doi.org/10.1207/S15324796A BM2401_04

Vidal, J. M. (2012, March 18). Los curas están estresados. [Priests are stressed]. El Mundo. http://www. elmundo.es/elmundo/2012/03/17/internacional/1331974559.html.

Virginia, S. G. (1998). Burnout and depression among Roman Catholic secular, religious, and monastic clergy. Pastoral Psychology, 47(1), 49-67. https://doi.org/10.1023/A:1022944830045

Walen, H. R., \& Lachman, M. E. (2000). Social support and strain from partner, family, and friends: Costs and benefits for men and women in adulthood. Journal of Social and Personal Relationships, 17(1), 5-30. https://doi.org/10.1177/0265407500171001

Ware, J., \& Gandek, B. (1994) The SF-36 Health Survey: Development and Use in Mental Health Research and the IQOLA Project. International Journal of Mental Health 23(2) 49-73 https://doi. org/10.1080/00207411.1994.11449283

Weaver, A. J., Larson, D. B., Flannelly, K. J., Stapleton, C. L., \& Koenig, H. G. (2002). Mental health issues among clergy and other religious professionals: A review of research. Journal of Pastoral Care \& Counsel, 56(4), 393-403. https://doi.org/10.1177/154230500205600408

Webb, B. L., \& Bopp, M. J. (2016). Results of Walking in Faith: A faith-based physical activity program for clergy. Journal of Religion and Health, 56, 561-574. https://doi.org/10.1007/ s10943-016-0255-2

Webb, B. L., \& Chase, K. (2019). Occupational distress and health among a sample of Christian clergy. Pastoral Psychology, 68(3), 331-343. https://doi.org/10.1007/s11089-018-0844-y

Wells, M. (2010). Resilience in older adults living in rural, suburban, and urban areas. Online Journal of Rural Nursing and Health Care, 10(2), 45-54. https://doi.org/10.14574/ojrnhc.v10i2.55

Wells, C. R. (2013). The effects of work-related and boundary-related stress on the emotional and physical health status of ordained clergy. Pastoral Psychology, 62(1), 101-114. https://doi.org/10.1007/ s11089-012-0455-y

Wells, C. R., Probst, J., McKeown, R., Mitchem, S., \& Whiejong, H. (2012). The relationship between work-related stress and boundary-related stress within the clerical profession. Journal of Religion and Health, 51(1), 215-230. https://doi.org/10.1007/s10943-011-9501-9

Wilson, C. B., \& Darling, C. A. (2017). Understanding stress and life satisfaction for children of clergy: A retrospective study. Pastoral Psychology, 66(1), 129-142. https://doi.org/10.1007/ s11089-016-0720-6

Helen R., Winefield Anthony H., Winefield Marika, Tiggemann (1992) Social Support and Psychological Well-Being in Young Adults: The Multi-Dimensional Support Scale. Journal of Personality Assessment 58(1) 198-210. https://doi.org/10.1207/s15327752jpa5801_17

Wingerden, J. V., \& Niks, I. M. W. (2017). Construction and validation of the perceived opportunity to craft scale. Frontiers in Psychology, 8(573), 1-9. https://doi.org/10.3389/fpsyg.2017.00573

World Health Organization [WHO]. (2018). CIE-11: Burnout. Retrieved March 13, 2021 from https://icd. who.int/browse11/1-m/en\#/http://id.who.int/icd/entity/129180281.

Zickar, M. J., Balzer, W. K., Aziz, S., \& Wryobeck, J. M. (2008). The moderating role of social support between role stressors and job attitudes among Roman Catholic priests. Journal of Applied Social Psychology, 38(12), 2903-2923. https://doi.org/10.1111/j.1559-1816.2008.00418.x 
Publisher's Note Springer Nature remains neutral with regard to jurisdictional claims in published maps and institutional affiliations.

\section{Authors and Affiliations}

Miguel Ruiz-Prada ${ }^{1}$ - Samuel Fernández-Salinero ${ }^{2}$. Cristina García-Ael ${ }^{1}$. Gabriela Topa' ${ }^{1}$

Miguel Ruiz-Prada

miguelruizprada@hotmail.com

Samuel Fernández-Salinero

samuel.fernandez@urjc.es

Cristina García-Ael

cgarciaael@psi.uned.es

1 Department of Social and Organizational Psychology, National University for Distance

Education, Madrid, Spain

2 Rey Juan Carlos University, Madrid, Spain 